\title{
A new CFD approach for proppant transport in unconventional hydraulic fractures.
}

\author{
SURI, Y., ISLAM, S.Z., HOSSAIN, M.
}




\title{
Keywords
}

Proppant transport; Hydraulic fracturing; Computational Fluid Dynamics; Discrete Element Method; Fluid Leak-off; Fracture Roughness

\section{Highlights-}

- $\quad$ Proppant transport in rough fractures with fluid leak-off from fracture wall

- $\quad$ Parametric study of proppant properties, fluid properties, and fracture properties

- $\quad$ Effect of using foam (Non-Newtonian) fracturing fluid

Yatin Suri, Sheikh Zahidul Islam*, and Mamdud Hossain

*Corresponding author. Email: s.z.islam1@rgu.ac.uk

Phone: +44(0)1224 262319

Fax: +44(0)1224262444

\begin{abstract}
-
For hydraulic fracturing design in unconventional reservoirs, the existing proppant transport models ignore the fluid leak-off effect from the fracture side wall and the effect of fracture recommended that neglecting the fracture roughness in the proppant transport model can result in over predicting the proppant bed length and underpredicting the proppant suspension layer by $10-15 \%$. Furthermore, neglecting the fluid leak-off effect can result in under predicting the proppant bed height by 10-50\% and over predicting the proppant suspension layer by 10-50\%. study has enhanced the understanding of the proppant-fracturing fluid interaction phenomenon by accounting detailed physics to optimise the hydraulic fracturing design.
\end{abstract}

\section{Graphical Abstract-}

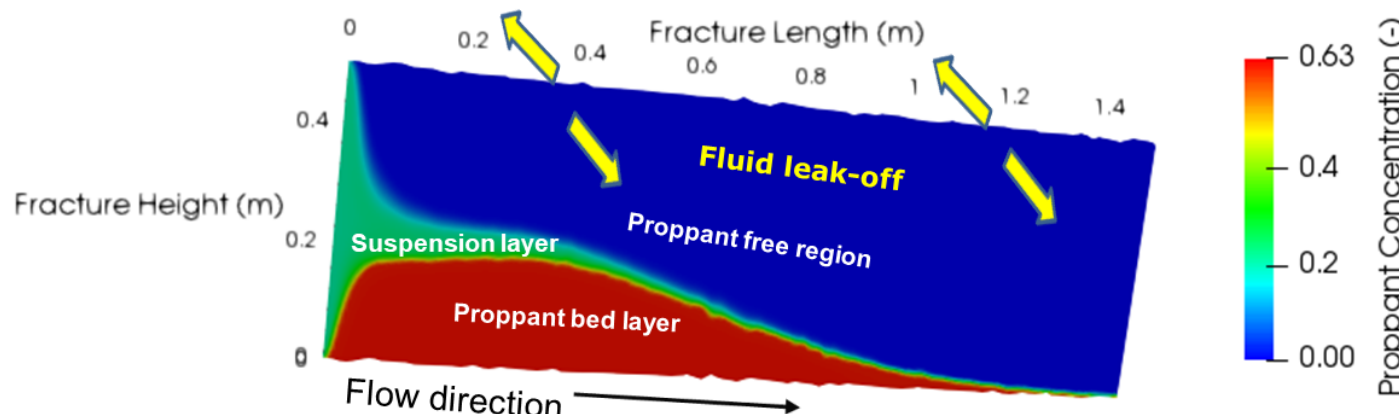


The advancements in the multistage hydraulic fracturing technology have resulted in the considerable progress in the hydrocarbon production in the last decade (Lange et al., 2013; Li et al., 2015; Yuan et al., 2018). Hydraulic fracturing is a technique in which fractures are initiated and propagated due to the injection of highly pressurised fluid at sufficiently high rates in the subsurface reservoir (Donaldson et al., 2014). When the fracture is estimated to be sufficiently long and wide, sand or other suitable material called proppants are injected with the additional fluid, to keep the fractures open against the rock pressure (Yew and Weng, 2014). The hydraulic fracturing in unconventional reservoirs is significantly different from the conventional reservoirs mainly because of the two reasons. Firstly, in conventional reservoirs, the focus of the hydraulic fracture design is to have a large fracture width, whereas, in the low permeability unconventional reservoir, greater fracture length is the prime factor to optimise (Belyadi et al., 2016). Secondly, slick water is commonly used as a fracturing fluid in the unconventional reservoir and due to the low viscosity of slick water and negligible chemical additive, tendency to suspend the proppant significantly decreases (Sahai et al., 2014). This results in early proppant deposition compared with conventional fracturing fluids (Alotaibi and Miskimins, 2015). Therefore, both of these attributes for the unconventional reservoirs, i.e. focus is on creating a longer fracture and early deposition of the proppants, result in closing of the unpropped section of the fracture, when hydraulic pressure is removed leading to reduced fracture conductivity (Donaldson et al., 2014; Belyadi et al., 2016).

Many experimental studies have been carried out to investigate the proppant transport in hydraulic fractures. The study of Kern et al. (1959) was among the earliest work on experimentally investigating the proppant transport and distribution with water flow using a vertical slot designed by two parallel Plexiglas plates. It was proposed that the proppant or sand injected early deposits around the wellbore and formed a proppant bed. The subsequent sand injected travels further along with the fluid flow and deposits away from the wellbore. Barree and Conway (1994) studied proppant distribution experiments to develop a numerical simulation tool and proposed the critical role of convection in proppant transport. Wang et al. (2003) and Gadde et al. (2004) used the laboratory data from STIM-LAB and proposed a model for proppant flow in fractures with smooth and rough surfaces respectively. Brannon et al. (2006) studied the characteristics of proppant slurry transport in a large-scale laboratory experiment. Sahai et al. (2014) performed the complex slot experiments to investigate the proppant distribution in fracture networks, and explained that pumping rate or injection rate and gravity effects play a significant role in transporting proppants from primary to secondary fracture branch. Alotaibi and Miskimins (2015) extended this work and studied the proppant bed height for a wide range of flow rates and proppant concentration. An analytical model was proposed to predict the proppant bed height in the primary fracture slot for 30/70 size sands. Recently, Tong and Mohanty $(2016,2017)$ investigated experimentally using water and foam as fracturing fluid in complex fractures. The experimental studies reported in the literature investigated the effects of proppant properties, fracturing fluid properties and, fracture geometry on the proppant distribution. However, due to the limitation of the laboratory scale, upscaling the results of proppant distribution to field scale could result in uncertainty. Hence, numerical methods can be used to validate the experimental data and upscale proppant transport physics to the field scale.

To capture the physics of proppant transport in fracturing fluid flow, the two key numerical approaches available in the literature are Eulerian-Lagrangian method and the EulerianGranular method (Gadde et al., 2004; Tsai et al., 2012). The Eulerian-Lagrangian method models the continuous phase by solving the mass and momentum conservation equations and the proppant phase is modelled by tracking their motion using Newton's second law of motion (Bokane et al., 2013). It provides a detailed analysis of particle-fluid and particle-particle interaction, and it is computationally costly, which provides a challenge to apply it to the field scale. Two most common Eulerian-Lagrangian methods used in the literature are the Discrete 
Particle (DPM) method and Computational Fluid Dynamics-Discrete Element Method (CFDDEM). They differ in the way particle-particle interaction is handled. The DPM model is used only for the low proppant concentration (10\%) and neglects inter-particle interaction. Further, the DPM model can track the trajectory of the proppants but fails when proppants settle and form a bed (Zhang et al., 2016). In the CFD-DEM model, the particle-particle/wall interactions more accurately captured using the soft-sphere approach, and unlike the DPM model, it can be used even for the higher proppant concentration. Accurate proppant distribution in this model results in substantially higher computational cost and limits its application for field scale fractures (Deng et al., 2014; Patankar, N. A. and Joseph, 2001; Snider, 2001; Wu and Sharma, 2016).

In the Eulerian-Granular methods also referred as Two-Fluid Model (TFM), the flow of particle and fluid phase is modelled using continuum medium, meaning both the phases are treated as a continuous phase and mass and momentum conservation equations are solved for both the phases separately. The model is based on Kinetic Theory of Granular Flow (KTGF) which captures the fluid-proppant and proppant-proppant interaction and provides a good approximation of the results in a computationally efficient manner, but detailed proppant-wall interaction is not considered in the Eulerian-Granular model (Clifton and Wang, 1988). Some of the key research work that studied proppant distribution using Eulerian-Granular method in detail is as follows (Clifton and Wang, 1988; Gadde et al., 2004; Kong et al., 2016; Liu, 2006; Roostaei et al., 2018).

The prediction of proppant distribution inside the fracture is a complex process, and some of the factors affecting the proppants are- fracture geometry, fracturing fluid properties and proppant properties. Schols and Visser (1974), Gu and Hoo (2014), Yang et al. (2017) extensively studied the proppant transport in the conventional reservoirs using high viscosity fracturing fluid and neglected the fluid leak-off from the fracture wall. However, in the low viscosity fracturing fluid (like slickwater) the proppant suspension is not a primary mechanism and as a result, proppant deposit quickly to form a proppant bed leading to dramatically shorter horizontal distance away from the wellbore. Furthermore, Wang et al. (2018), Hu et al. (2018) numerically studied the proppant transport and distribution using slickwater as fracturing fluid but simplified the model with assuming smooth planar geometry, laboratory scale model and neglecting fluid leak-off from the fracture wall. To the best of our knowledge, the current models are described for planar and smooth fracture geometry without fluid leak-off behaviour, and in the present study, an attempt has been made to overcome this challenge to capture the proppant physics in a rough fracture with fluid leak-off from fracture wall. Additionally, Kong et al. (2016) described that foam could be used as an alternative to slickwater as a fracturing fluid in shale gas reservoirs as it has high apparent viscosity and lower leak off which aids in proppant suspension. Gu and Mohanty (2014) also explained that foam could assist in faster fracture clean-up due to gas expansion and reported that the foam stability depends upon temperature, pressure, gas type, surfactant and concentration. Use of foam as a fracturing fluid has been experimentally studied by many researchers using Hele-Shaw slots in a laboratory scale model (Hosseini et al., 2018; Tong et al., 2017; Tong et al., 2018). In the current study, the proppant distribution for foam as a fracturing fluid is investigated using numerical modelling.

In this paper, a hybrid model is proposed which is a combination of CFD-DEM and Eulerian Granular method. It solves the mass and momentum conservation equations to model the continuous phase, and the proppant phase is modelled in the Lagrangian frame by tracking their motion using Newton's second law of motion. However, the proppants are mapped back to the Eulerian grid. The inter-proppant interaction is modelled by KTGF, and the proppant-wall interaction is modelled using the Lagrangian method. It overcomes the challenges of EulerianGranular method and is computationally faster than Eulerian-Lagrangian methods. Like CFDDEM, the hybrid can be used for higher volume fraction. The current paper aims to use the 
hybrid method and investigate the effect of proppant transport in rough fracture geometry. The reported models in the literature are described for planar and smooth fracture geometry without fluid leak-off behaviour. In the present study, an attempt has been made to overcome this challenge to capture proppant physics in a rough fracture. The model also incorporates the fluid leak-off from the fracture walls for slickwater and Non-Newtonian fracturing fluid (foam). First, the proppant model is validated with the published experimental results. Subsequently, a base case simulation of the proppant transport and distribution in a real and rough fracture geometry is presented with fluid leak-off. Then, a series of case studies are designed to evaluate the impact of using Non-Newtonian fluid (foam), variation in injection velocity, injection proppant concentration, and fracture height.

\section{Methodology}

In the present study, a hybrid numerical model is used to study proppant transport and distribution in hydraulic fractures, described in the following sections. The principal objective in the present study is to provide a detailed understanding of the proppant transport considering the effect of fluid leak-off from the fracture wall in a rough fracture geometry in the unconventional reservoir. Some of the assumptions underlying the current model are as follows: First, the base model is small scale. Second, no dynamic fracture propagation is considered in this study.

\section{Flow Governing Equations}

The hybrid model is a combination of CFD-DEM and Eulerian-Granular method. It solves the mass and momentum conservation equations to model the continuous phase, and the proppant is tracked by calculating and tracking the mass, velocity, and forces acting on a particle using Newton's second law of motion. This is referred to as tracking in the Lagrangian frame in the hybrid method. However, the proppants are mapped back to the Eulerian grid. Like CFD-DEM, the hybrid model can be used for higher volume fraction ( $>10 \%)$. It overcomes the challenges of Eulerian-Granular method and is computationally faster than CFD-DEM. The inter-proppant interaction is modelled by KTGF, and the proppant-wall interaction is modelled using the Lagrangian method.

The Navier-Stokes equations (mass and momentum conservation equations) of the continuous phase (fracturing fluid) and proppant phase are described below. The equations assume isothermal and incompressible condition for the fracturing fluid. The detailed derivation of these equations can be found in Banerjee and Chan (1980), Versteeg and Malalasekera (2007) and Jakobsen (2014).

The mass conservation equation is given by:

$$
\rho_{\mathrm{i}}\left(\frac{\partial}{\partial \mathrm{t}} \alpha_{\mathrm{i}}+\nabla \cdot \alpha_{\mathrm{i}} \overrightarrow{\mathrm{v}}_{\mathrm{i}}\right)=\mathrm{S}_{\mathrm{m}}
$$

Where $\alpha$ represents volume fraction, $\rho$ refers to the density, $v$ refers to velocity, $S_{m}$ refers to mass source term and subscript i refers to phase (liquid or solid)

$$
\sum_{i}^{n} \alpha_{i}=1
$$

For the fracturing fluid the conservation of momentum equation is given by:

$$
\frac{\partial}{\partial \mathrm{t}}\left(\alpha_{1} \rho_{\mathrm{l}} \overrightarrow{\mathrm{v}}_{\mathrm{l}}\right)+\nabla \cdot\left(\alpha_{1} \rho_{\mathrm{l}} \overrightarrow{\mathrm{v}}_{\mathrm{l}} \overrightarrow{\mathrm{v}}_{\mathrm{l}}\right)=-\alpha_{\mathrm{l}} \nabla_{\mathrm{p}}+\nabla \cdot \overline{\overline{\mathrm{\tau}}}_{\mathrm{l}}+\alpha_{\mathrm{l}} \rho_{\mathrm{l}} \mathrm{g}+\overrightarrow{\mathrm{M}}_{\mathrm{ls}}+\mathrm{S}_{\mathrm{u}}
$$

Where g refers to acceleration due to gravity, $\overrightarrow{\mathrm{M}_{\mathrm{ls}}}=\overrightarrow{\mathrm{M}_{\mathrm{sl}}}$ refers to the interfacial momentum exchange between the fluid and proppant phase, $S_{u}$ refers to the momentum source term and $\overline{\overline{\tau_{1}}}$ is the fluid phase stress-strain tensor given by:

$$
\overline{\bar{\tau}}_{1}=\alpha_{1} \mu_{1}\left(\nabla \overrightarrow{\mathrm{v}}_{1}+\nabla \overrightarrow{\mathrm{v}}_{\mathrm{l}}^{\mathrm{T}}\right)+\alpha_{\mathrm{l}}\left(\lambda_{1}-\frac{2}{3} \mu_{1}\right) \nabla \cdot \overrightarrow{\mathrm{v}}_{\mathrm{l}} \overline{\bar{I}}^{\mathrm{I}}
$$

Where $\lambda_{1}$ and $\mu_{1}$ refer to the bulk viscosity and dynamic viscosity of continuous phase (fracturing fluid) respectively. 
The distribution of discrete phase proppant motion is calculated by integrating the force balance on the proppant, which is written in a Lagrangian reference frame. Using Newton's second law of motion, the governing equations of the proppant motion can be defined as follows:

$$
\begin{gathered}
\mathrm{m} \frac{\mathrm{d} \overrightarrow{\mathrm{v}}_{\mathrm{p}}}{\mathrm{dt}}=\overrightarrow{\mathrm{F}}_{\text {drag }}+\overrightarrow{\mathrm{F}}_{\text {gravitation }}+\overrightarrow{\mathrm{F}}_{\text {KTGF }} \\
\frac{\mathrm{dx} \mathrm{x}_{\mathrm{p}}}{\mathrm{dt}}=\overrightarrow{\mathrm{v}_{\mathrm{p}}}
\end{gathered}
$$

The above equations can be re-written in the following form as

$$
\frac{\mathrm{d} \overrightarrow{\mathrm{v}}}{\mathrm{dt}}=\frac{\overrightarrow{\mathrm{v}_{1}}-\overrightarrow{\mathrm{v}_{\mathrm{p}}}}{\tau_{\mathrm{r}}}+\frac{\mathrm{g}\left(\rho_{\mathrm{p}}-\rho\right)}{\rho_{\mathrm{p}}}+\overrightarrow{\mathrm{F}}_{\mathrm{KTGF}}
$$

The velocity and spatial location of discrete particles are calculated using Eq. (7) and Eq. (6) respectively. The term $\overrightarrow{\mathrm{F}}_{\mathrm{KTGF}}$, refers to inter-particle interaction force from KTGF and can be calculated by-

$$
\overrightarrow{\mathrm{F}}_{\text {KTGF }}=-\frac{1}{\alpha_{\mathrm{s}} \rho_{\mathrm{s}}} \nabla \cdot \overline{\bar{\tau}}_{\mathrm{s}}
$$

Where $\overline{\overline{\tau_{s}}}$ refers to the stress-strain tensor for proppant phase.

The variable $\tau_{r}$ is the droplet or particle relaxation time given by-

$$
\tau_{\mathrm{r}}=\frac{\rho_{\mathrm{p}} \mathrm{d}_{\mathrm{p}}^{2}}{18 \mu} \frac{24}{\mathrm{C}_{\mathrm{D}} \mathrm{Re}}
$$

$\frac{\overrightarrow{v_{1}}-\overrightarrow{v_{p}}}{\tau_{r}}$ is the drag force per unit particle mass, $\overrightarrow{v_{l}}$ and $\overrightarrow{v_{p}}$ are the fluid and particle velocity respectively, $\mu$ is the fluid viscosity, $\rho$ and $\rho_{p}$ are the fluid and particle density respectively, $d_{p}$ is the particle diameter, and $R e$ is the Reynolds number, defined as

$$
\operatorname{Re}=\frac{\rho d_{\mathrm{p}}\left|\overrightarrow{\mathrm{v}_{\mathrm{p}}}-\overrightarrow{\mathrm{v}_{1}}\right|}{\mu}
$$

The drag force modelling and the stress terms are described in detail below.

\subsection{Drag Force Modelling}

The drag force is described by the Eq. (11). Numerous drag force models are available for multiphase flow modelling that differs in the definition of inter-phase momentum exchange coefficient, $\mathrm{K}_{\mathrm{ls}}$ or $\mathrm{K}_{\mathrm{sl}}$.

$$
\overrightarrow{\mathrm{F}}_{\mathrm{drag}}=\mathrm{K}_{\mathrm{ls}}\left(\overrightarrow{\mathrm{v}}_{1}-\overrightarrow{\mathrm{v}}_{\mathrm{s}}\right)
$$

$\overrightarrow{v_{l}}-\overrightarrow{v_{s}}$ is the relative velocity between the phases. Gidaspow (1994) proposed a drag force model which provides the flexibility to use it for a wider application range based on the proppant volume fraction. Gidaspow drag model is used in the present study as described by Eq. (12):

$$
K_{s l}= \begin{cases}150 \frac{\alpha_{s}\left(1-\alpha_{1}\right) \mu_{1}}{\alpha_{1} d_{s}^{2}}+1.75 \frac{\rho_{1} \alpha_{s}\left|\vec{v}_{s}-\vec{v}_{1}\right|}{d_{s}} & \text { if } \alpha_{s}>0.2 \\ \frac{3}{4} C_{D} \frac{\rho_{1} \alpha_{s} \alpha_{1}\left|\vec{v}_{s}-\vec{v}_{1}\right|}{d_{s}} \alpha_{1}-2.65 & \text { if } \alpha_{s}<0.2\end{cases}
$$

Where $d_{s}$ represents the proppant phase diameter and $C_{D}$ refers to the drag coefficient and calculated by equation (13).

$$
C_{D}= \begin{cases}\frac{24}{\alpha_{1} \cdot R_{s}}\left[1+0.15\left(\alpha_{1} \cdot R_{S}\right)^{0.687}\right] & \text { if } \alpha_{1} \cdot \operatorname{Re}<1000 \\ 0.44 & \text { if } \alpha_{1} \cdot \operatorname{Re}>1000\end{cases}
$$

Where $\operatorname{Re}_{\mathrm{s}}$ refers to the Reynolds number of the proppant phase and calculated by:

$$
\operatorname{Re}_{\mathrm{s}}=\frac{\rho_{1} \mathrm{~d}_{\mathrm{s}}\left|\overrightarrow{\mathrm{v}}_{\mathrm{s}}-\overrightarrow{\mathrm{v}}_{\mathrm{v}}\right|}{\mu_{\mathrm{l}}}
$$

\subsection{Stresses Model for the proppant phase}

Savage and Jeffrey (1981) described that the solid stress for the proppant phase, $\overline{\overline{\tau_{s}}}$ (in Eq. (8)) is based on the kinetic theory of granular flow (KTGF) models as expressed in Eq. (16)

$$
\overline{\bar{\tau}}_{s}=\left(-P_{s}+\lambda_{s} \nabla \cdot \mu_{s}\right) I+\mu_{s}\left\{\left[\nabla \mu_{s}+\left(\nabla \mu_{s}\right)^{\mathrm{T}}\right]-\frac{2}{3}\left(\nabla \cdot \mu_{s}\right) \overline{\bar{I}}\right\}
$$


Where $\lambda_{\mathrm{s}}$ and $\mu_{\mathrm{s}}$ refer to the bulk viscosity and dynamic viscosity of the granular phase respectively and $\overline{\bar{I}}$ is the unit tensor.

245

\subsection{Granular Temperature}

The granular temperature is one of the critical parametersto model proppant laden fluid flow as it is a function of the specific kinetic energy of the particle velocity fluctuations, as expressed in equation (16).

$$
\Theta_{\mathrm{s}}=\frac{1}{3}\left\langle\mathrm{v}_{\mathrm{s}}^{2}\right\rangle
$$

Where $\Theta_{s}$ refer to the granular temperature, $v_{S}$ refer to the granular phase velocity fluctuation. Thus, the granular energy transport equation is given by equation (17).

$$
\frac{3}{2}\left[\frac{\partial}{\partial \mathrm{t}}\left(\alpha_{\mathrm{s}} \rho_{\mathrm{s}} \Theta_{\mathrm{s}}\right)+\nabla \cdot\left(\alpha_{\mathrm{s}} \rho_{\mathrm{s}} \Theta_{\mathrm{s}}\right) \overrightarrow{\mathrm{v}}_{\mathrm{s}}\right]=\left(-\mathrm{P}_{\mathrm{s}} \overline{\overline{\mathrm{I}}}+\overline{\bar{\tau}}_{\mathrm{s}}\right): \nabla \overrightarrow{\mathrm{v}}_{\mathrm{s}}+\nabla \cdot\left(\mathrm{k}_{\Theta_{\mathrm{s}}} \nabla \Theta_{\mathrm{s}}\right)-\gamma_{\Theta_{\mathrm{s}}} \Phi_{\mathrm{ls}}
$$

Where $\Phi_{\mathrm{ls}}$ refers to the interphase granular energy transfer, $\gamma_{\Theta \mathrm{s}}$ is the granular energy dissipation rate due to an inelastic collision, $\mathrm{k}_{\Theta_{\mathrm{s}}}$ is the diffusion coefficient and $\alpha_{\mathrm{s}}$ refer to the granular phase volume fraction. There are two ways of calculating the granular temperature. Firstly, by solving the transport equation (17) and secondly, using an algebraic expression. Van Wachem et al. (2001) proposed an algebraic expression described by equation (18) assuming the steady-state solution of the granular energy and neglected the convection and diffusion terms.

$$
0=\left(-\mathrm{P}_{\mathrm{S}} \overline{\overline{\mathrm{I}}}+\overline{\bar{\tau}}_{\mathrm{s}}\right): \nabla \overrightarrow{\mathrm{v}}_{\mathrm{S}}:-\gamma_{\Theta_{\mathrm{s}}} \Phi_{\mathrm{ls}}
$$

\subsection{Granular Phase Pressure Model}

Lun et al. (1984) proposed a correlation for calculating the pressure for granular phase, $\mathrm{P}_{\mathrm{s}}$ that relates to the normal force acting as a result of particles motion, described by equation (19).

$$
\mathrm{P}_{\mathrm{s}}=\rho_{\mathrm{s}} \alpha_{\mathrm{s}} \Theta_{\mathrm{s}}+2 \rho_{\mathrm{s}} \alpha_{\mathrm{s}}^{2} \Theta_{\mathrm{s}}\left(1+\mathrm{e}_{\mathrm{ss}}\right) \mathrm{g}_{0, \mathrm{ss}}
$$

Where, $e_{\mathrm{ss}}$ refers to the restitution coefficient due to particles collision, which can vary from 0 to 1 corresponding to from perfectly inelastic to a perfectly elastic collision. Inelastic particle collision with a restitution coefficient of 0.9 is assumed in this study, based on the study of Basu et al. (2015). Lun et al. (1984) proposed the model for the probability radial distribution function of particle contacting another particle, $\mathrm{g}_{0, \mathrm{~s}}$, given by equation (20).

$$
\mathrm{g}_{0, \mathrm{ss}}=\left[1-\left(\frac{\alpha_{\mathrm{s}}}{\alpha_{\mathrm{s}, \max }}\right)^{\frac{1}{3}}\right]^{-1}
$$

Where, $\alpha_{\mathrm{s}, \max }$ refers to the maximum packing limit for the granular phase. It was described by Lun et al. (1984) that for uniform proppant size, the maximum packing is 0.63 . The present study also deals with identical size proppants and thus 0.63 maximum packing limit is used.

\subsection{Granular Shear Viscosity}

The granular shear viscosity is one of the vital parameters and is modelled as a sum of the kinetic $\mu_{\mathrm{s}, \mathrm{kin}}$, collisional $\mu_{\mathrm{s}, \mathrm{col}}$ and frictional viscosity $\mu_{\mathrm{s}, \mathrm{fr}}$, as expressed in Equation (21)

$$
\mu_{\mathrm{s}}=\mu_{\mathrm{s}, \mathrm{kin}}+\mu_{\mathrm{s}, \mathrm{col}}+\mu_{\mathrm{s}, \mathrm{fr}}
$$

Gidaspow et al. (1991), Gidaspow (1994) and Johnson and Jackson (1987) models given in Equation (22, 23 and 24) respectively are used to account for the kinetic viscosity, collisional viscosity, and frictional viscosity.

$$
\begin{aligned}
& \mu_{s, \text { kin }}=\frac{10 \rho_{\mathrm{s}} \mathrm{d}_{\mathrm{s}} \sqrt{\Theta_{\mathrm{s}} \pi}}{96 \alpha_{\mathrm{s}} \mathrm{g}_{0, \mathrm{ss}}\left(1+\mathrm{e}_{\mathrm{ss}}\right)}\left[1+\frac{4}{5} \alpha_{\mathrm{s}} \mathrm{g}_{0, \mathrm{ss}}\left(1+\mathrm{e}_{\mathrm{ss}}\right)\right]^{2} \\
& \mu_{\mathrm{s}, \mathrm{col}}=\frac{4}{5} \alpha_{\mathrm{s}} \rho_{\mathrm{s}} \mathrm{d}_{\mathrm{s}} \mathrm{g}_{0, \mathrm{ss}}\left(1+\mathrm{e}_{\mathrm{ss}}\right)\left(\frac{\Theta_{\mathrm{s}}}{\pi}\right)^{\frac{1}{2}} \\
& \mu_{\mathrm{s}, \mathrm{fr}}=\mathrm{P}_{\mathrm{sf}} \sin \theta
\end{aligned}
$$


Where $\theta$ refers to the angle of friction defined as $30^{\circ}$ and $\mathrm{P}_{\text {sf }}$ refers to the friction pressure defined by the Johnson and Jackson (1987) model described by equation (25).

$$
P_{s f}=F_{r} \frac{\left(\alpha_{s}-\alpha_{s, \min }\right)^{n}}{\left(\alpha_{s, \max }-\alpha_{s}\right)^{p}}
$$

Where, the constants $\mathrm{Fr}=0.1 \alpha_{\mathrm{s}}, \mathrm{n}=2$, and $\mathrm{p}=5 . \alpha_{\mathrm{s}, \min }$ is the granular phase volume fraction at which friction becomes dominant (approximately 0.6 ) and $\alpha_{\mathrm{s}, \max }$ is the maximum packing limit as explained earlier.

\section{Modelling workflow and simulation parameters}

The CFD modelling of proppant transport in hydraulic fractures was studied using ANSYS FLUENT 18.1. The modelling workflow along with the simulation parameters used in the study can be summarised in the following steps:

\subsection{Geometry/Computational domain}

The hydraulic fracture can be of a variable size from centimetres scale to several meters scale. In the present study, the computational domain involves a three-dimensional rough fracture with dimensions $1.5 \mathrm{~m} \times 0.5 \mathrm{~m} \times 0.005 \mathrm{~m}$, length $\times$ height $\times$ width respectively, as shown in Fig. 1. The fracture profile was created using SynFrac software (Ogilvie et al., 2006) which followed the normal distribution fracture height with a mean of $0.5 \mathrm{~m}$ and a standard deviation of $2 \mathrm{~mm}$. The mean fracture aperture used was $5 \mathrm{~mm}$. The method from Briggs et al. (2017) was used to generate a rough fracture model. The fracture profile is shown in Fig. 1 and the histogram showing the normal distribution of the fracture height is shown in Fig. 2.

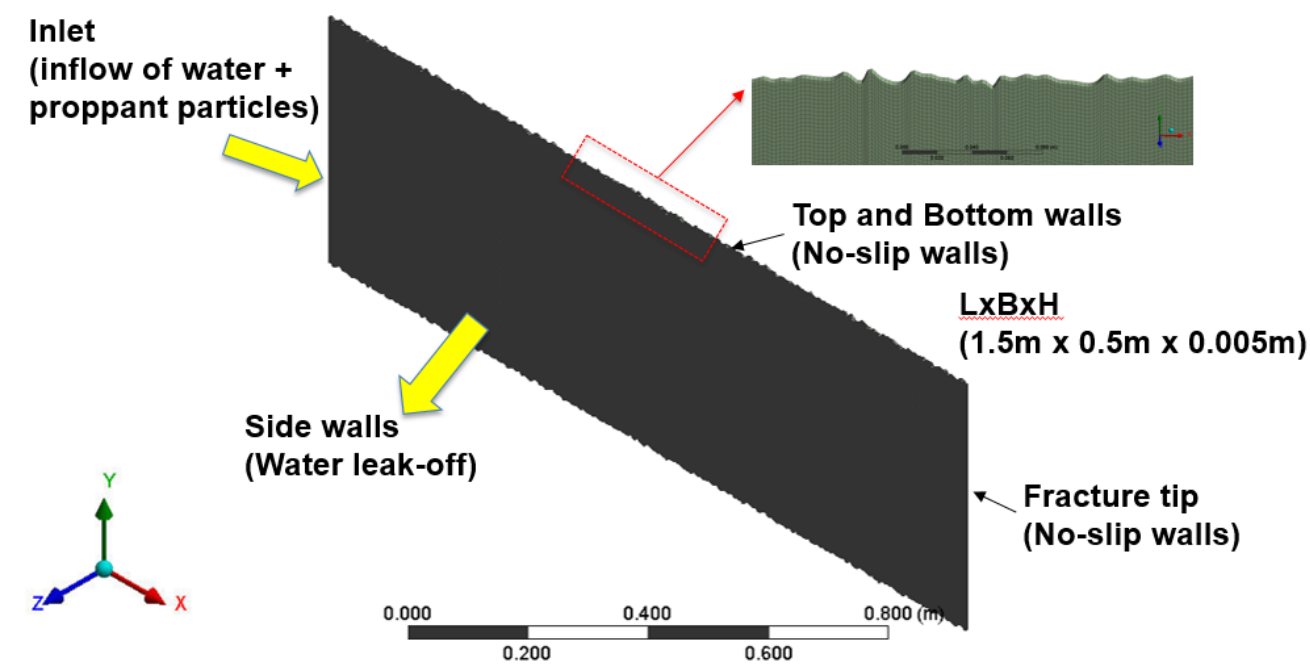

308 Fig. 1 Computational domain and boundary conditions used in the study

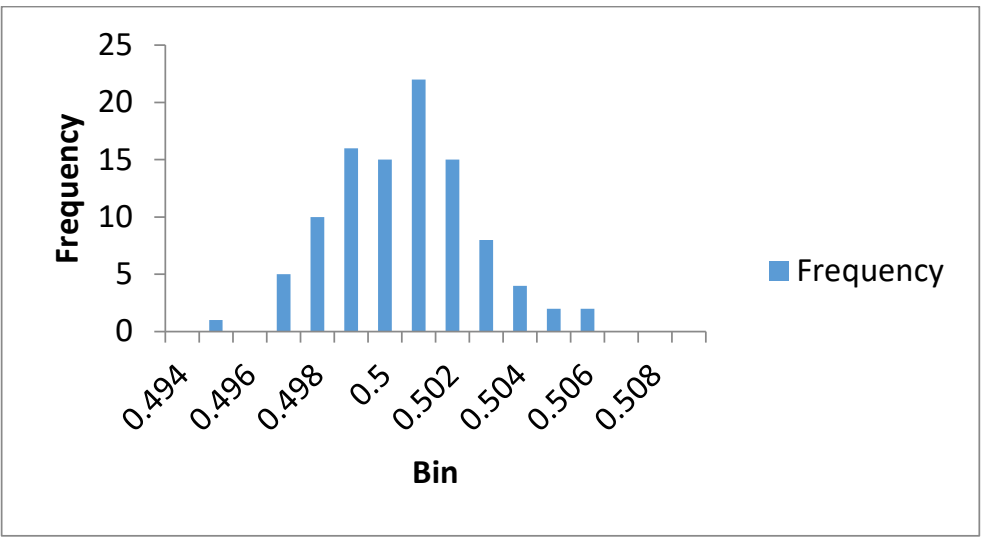

Fig. 2 Histogram showing the normal distribution of fracture height with roughness 
The mesh sensitivity study was carried out to investigate the mesh independent solution with mesh sizes $0.002 \mathrm{~m}, 0.0025 \mathrm{~m}, 0.003 \mathrm{~m}$, and $0.004 \mathrm{~m}$. The results are presented in Fig. 3a and $3 \mathrm{~b}$ showing the proppant volume fraction vs fracture height and proppant axial velocity vs fracture height at a cross section of $0.1 \mathrm{~m}$ from the inlet. Based on the mesh sensitivity study, the mesh was generated in the computational grid evenly distributed in all direction with size $0.0025 \mathrm{~m}(600 \times 200 \times 2$ elements $)$. The computational mesh was selected to provide good quality mesh, numerically converged and mesh independent solution with reasonable computational cost. To include the fracture roughness along the side walls of the fracture, wall surface roughness height and roughness constant were modified to $0.0005 \mathrm{~m}$ and 0.5 respectively based on the study of (Blocken et al., 2007).

a.

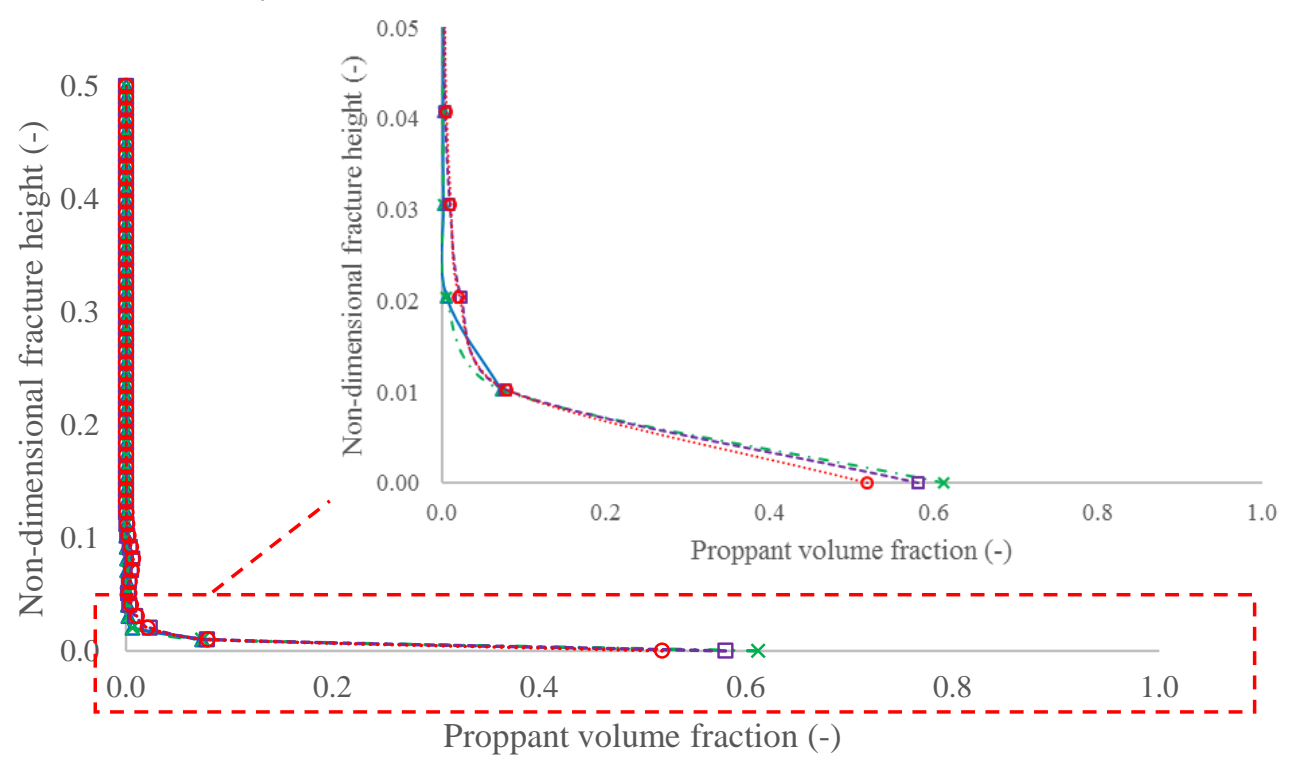

b.

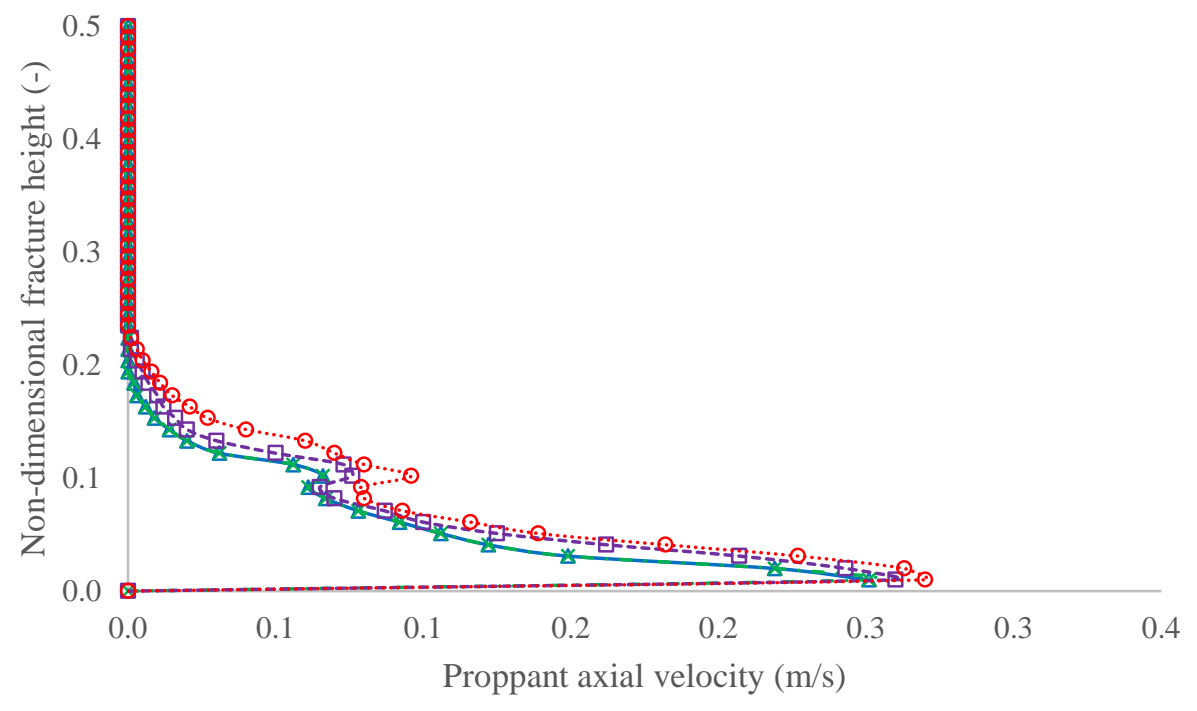

Legend

$$
\begin{gathered}
\longrightarrow-\text { Mesh size }=0.002 \mathrm{~m} \\
--x-M e s h \text { size }=0.0025 \mathrm{~m} \\
\cdots-- \text { Mesh size }=0.003 \mathrm{~m} \\
\cdots \cdots-\text { Mesh size }=0.004 \mathrm{~m}
\end{gathered}
$$

Fig. 3 Mesh sensitivity study- comparison of numerical results with different mesh sizes a) plot of proppant volume fraction vs fracture height b) plot of proppant axial velocity vs fracture height 
Post-injection of fracturing fluid into the wellbore, the process of fluid flowing from the fracture wall to the surrounding porous rock is called leak-off (Carter, 1957). In order to account for the fracturing fluid leak-off effects in proppant transport and distribution, a separate steady state simulation using CFD solver was carried out to calculate the water leaking off rate along the fracture side wall. A similar fracture configuration, as described in section 4.1, is used and is surrounded by a porous and permeable shale rock with porosity $5 \%$ and permeability $0.1 \mathrm{mD}$ (Speight, 2016), as shown in Fig. 4. The key governing equations solved for the fluid flow from the fracture to porous media are as follows-

\subsubsection{Continuity equation}

In an isothermal system the continuity equation for a steady state, incompressible condition can be defined as-

$$
\nabla \cdot v_{i}=0
$$

Where $v_{i}$ is the velocity vector.

\subsubsection{Momentum equation}

The Navier-Stokes equation was used to model the momentum change in porous media defined in Eq. (27). The Eq. (26) and Eq. (27) are based on isothermal, steady state, incompressible condition assumptions and thus the transient terms are neglected.

$$
\rho\left(v_{i} . \nabla\right) v_{i}=-\nabla P+\mu \nabla^{2} v_{i}+F_{i}
$$

where $\mu$ is the fluid viscosity, $\rho$ is the fluid density, $P$ is the static pressure, and $F_{i}$ is the source term to account for the flow through porous media, and can be calculated by rearranging the Darcy's Law.

$$
\mathrm{F}_{\mathrm{i}}=-\frac{\mu}{\mathrm{k}} \mathrm{v}_{\mathrm{i}}
$$

Where $\mathrm{k}$ is the permeability of the reservoir. The surrounding porous rock was assumed to be isotropic and $\mathrm{k}$ was assumed to be homogenous.

The velocity boundary condition was used at the inlet where water was injected with an injection velocity of $0.5 \mathrm{~m} / \mathrm{s}$, and pressure boundary condition was used with one atmospheric pressure applied at the outlet. The fracture wall was assumed to be porous, and the percentage of injected water mass lost/leaked from the fracture side walls is calculated along the fracture length, as shown in Fig. 5. A user-defined function (UDF) is subsequently defined and written in $\mathrm{C}++$ which is interpreted by the CFD solver (ANSYS FLUENT 18.1) to model the fluid leak-off and add a mass and momentum source term in the proppant transport governing equations (Eq. (1) and Eq. (3)). The source terms in the governing equations are defined as zero for all regions of the model except the fracture side walls. In the fracture geometry of Fig. 1, at the side walls, the fluid leakage effect is introduced with the help of user-defined function (UDF). This is done to mimic the fluid leak-off into the porous reservoir, leaving the proppant in the fracture.

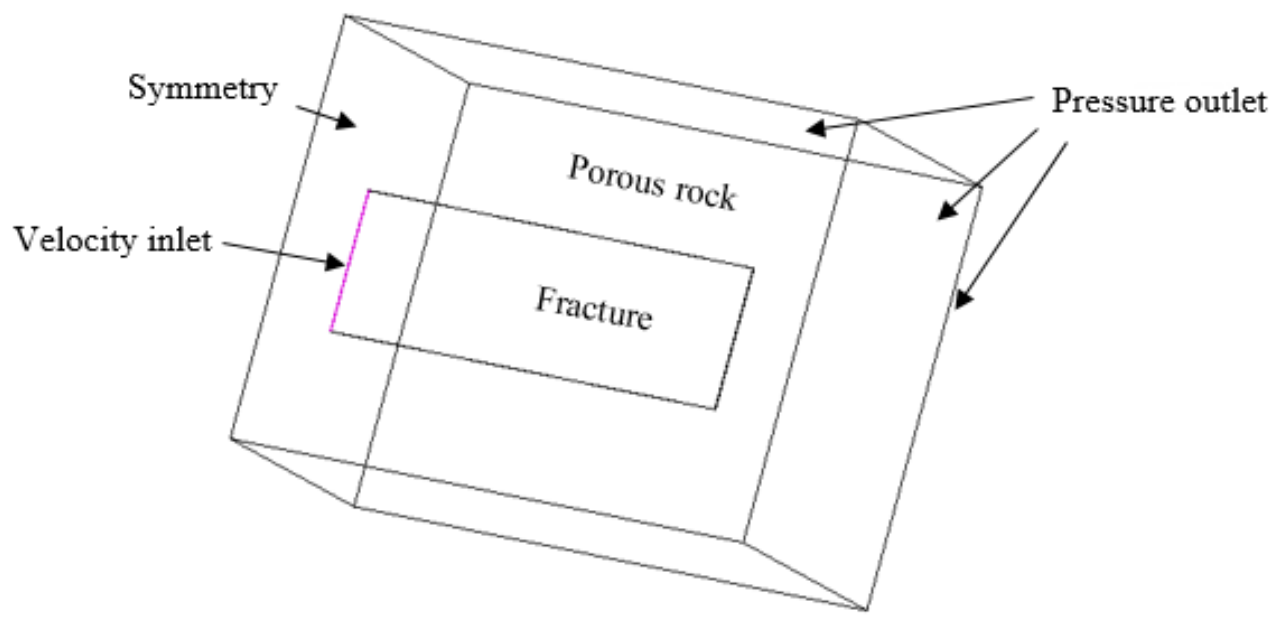

Fig. 4 Fracture surrounded by porous rock 


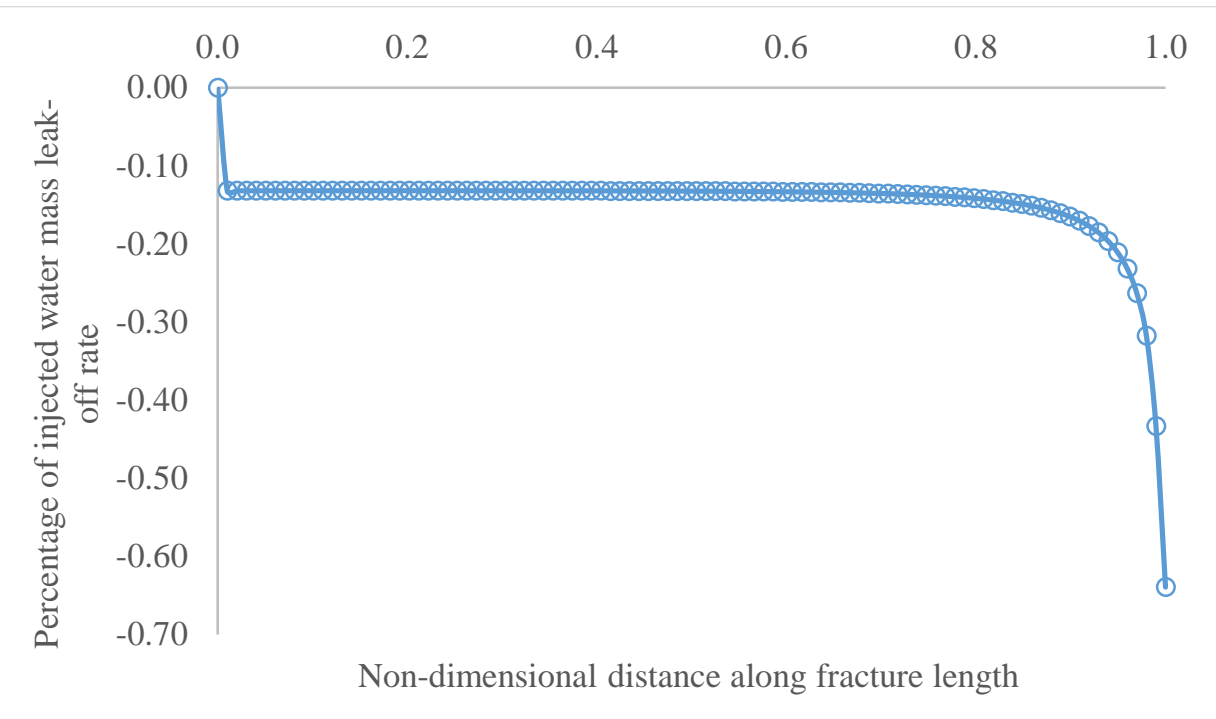

Fig. 5 Fluid Leak-off rate at fracture wall along the fracture length

\subsection{Simulation set up}

Next, appropriate boundary conditions and simulation properties were defined. A velocity inlet boundary condition is used at the inlet where fluid and proppants are injected at $0.5 \mathrm{~m} / \mathrm{s}$. The Rosin-Rammler particle size distribution is assumed based on the 20/40 size sand. The top, bottom walls and fracture tip were specified as no-slip stationary walls as shown in Fig. 1. In the side walls, the fluid leakage effect is introduced with the help of user-defined function (UDF). This is done to mimic the fluid leak-off into the porous reservoir, leaving the proppant in the fracture. The momentum and mass source terms are defined and included in the governing equations through UDFs as described in modelling leak-off section. The fluid leakage rate along the fracture length used in the study is shown in Fig. 5.

A transient state simulation with pressure-based solver and gravitation effects was configured. The pressure-based solver was selected due to the incompressible nature of the studied fluid. The transient state was selected to understand the proppant transport phenomenon with time. The turbulence model used was the Shear Stress Transport (SST) k- $\omega$ model (Menter, 1993). The SST k- $\omega$ turbulence model is a two-equation eddy-viscosity model, which combines standard $k-\omega$ turbulent model in the boundary layer (low-Re region) with the standard k- $\varepsilon$ turbulent model in the free-stream (Menter, 1993). One of the most significant advantages of using the SST k- $\omega$ model is that it also provides excellent results in adverse pressure gradients and separating flow (Versteeg and Malalasekera, 2007). The fluid and proppant properties are listed in Table 1.

\section{Table 1}

Physical properties of proppant and fluid used in the simulation

\begin{tabular}{|l|l|}
\hline Proppant diameter & $20 / 40$ size sand \\
\hline Proppant density & $2650 \mathrm{~kg} / \mathrm{m}^{3}$ \\
\hline Fluid density & $1000 \mathrm{~kg} / \mathrm{m}^{3}$ \\
\hline Fluid inlet velocity & $0.5 \mathrm{~m} / \mathrm{s}$ \\
\hline Fluid viscosity & $0.001 \mathrm{~Pa}-\mathrm{s}(1 \mathrm{cP})$ \\
\hline Proppant volume fraction & 0.20 \\
\hline
\end{tabular}


The viscosity of the granular phase is calculated from the Gidaspow (1994) correlation. The primary role of granular viscosity is used to consider the frictional losses. The frictional viscosity refers to the shear viscosity based on the viscous-plastic flow and is calculated using the Johnson and Jackson (1987) correlation. The packing limit defines the maximum volume fraction of the granular phase, which was used as 0.63 based on the study of Basu et al. (2015). Friction packing limit refers to a threshold volume fraction at which the frictional regime becomes dominant, and friction packing limit of 0.6 is used.

In the Eulerian-Granular method, the drag force used to model the interaction between the two phases is based on Gidaspow drag law (1994) and the collision between the proppant particles is modelled using the restitution coefficient as explained in the methodology.

The time step used in the simulation was $0.001 \mathrm{~s}$. The reflect DPM boundary condition used at walls so that the particles will reflect after the collision with the wall. velocity coupling (Patankar, S., 1980; Versteeg and Malalasekera, 2007). The node-based averaging scheme is used to apply the parcel approach (Mahdavi et al., 2015). The discretisation of momentum, volume fraction, and turbulent kinetic energy was solved by the second-order upwind scheme.

\section{Results and Discussion}

\subsection{Comparison with the experimental results}

The present simulation model was compared against the experimental study of Tong and Mohanty (2016). The simulation was performed with the geometry similar to the experimental setup. All the modelling parameters are presented in Table 2, which are similar to experimental parameters. The hybrid model was used to model the fluid flow and proppant distribution. Fracturing fluid (water, in this case) along with the proppant is injected at the inlet.

Fig. 6 shows a comparison of experimental and simulation results at time $=20 \mathrm{~s}$ after the start of injection for different injection velocities. The contour plot shows a similar distribution to the experimental results. To quantitatively compare the results, dimensionless equilibrium height and dimensionless length at the centre of proppant bed are plotted in Fig. 6 for all the cases.

The results of dimensionless equilibrium height are also compared with an analytical model by Wang et al. (2003) described as follows-

$$
\begin{aligned}
& \frac{\mathrm{H}-\mathrm{Ho}}{\mathrm{w}}=\left[-2.3 \times 10^{-4} \ln \left(\mathrm{R}_{\mathrm{gp}}\right)+2.92 \times 10^{-3}\right] \times \mathrm{Re}_{1}^{1.2-1.26 \times 10^{-3} \mathrm{R}_{\mathrm{gl}}^{-0.428}\left[15.2-\ln \left(\mathrm{R}_{\mathrm{gp}}\right)\right]} \times \\
& \mathrm{Re}_{\mathrm{p}}^{\left[-0.0172 \ln \left(\mathrm{R}_{\mathrm{gp}}\right)-0.12\right]}
\end{aligned}
$$

Where $\mathrm{H}, \mathrm{Ho}$ and $\mathrm{w}$ are the height of slot, the height of slurry flow area and the width of slot respectively. $\mathrm{Re}_{1}$ and $\mathrm{Re}_{\mathrm{p}}$ are the Reynolds number for the fluid and proppant phase respectively. The $R_{g l}$ and $R_{g p}$ are the gravity Reynolds number for the fluid and proppant phase respectively. Detailed definition of $R_{f}, R_{p}, \lambda_{f}$ and $R_{g}$ can be found in Wang et al. (2003). The experimental results and the numerical results are compared in Fig. 8.

Fig. 7 and Fig. 8 shows a good match among the experimental study and the current simulation. The average error in dimensionless equilibrium height and dimensionless length at the centre of proppant bed is $3.2 \%$ and $3 \%$ respectively between the current simulation and the experiment, which suggests a reasonable match with the experiment. The error can be attributed to the secondary fracture present in the experimental setup, which can result in proppant entering into secondary fractures and reduction in proppant bed length in the primary fracture. The average error in dimensionless equilibrium height, between the current model and the analytical model by Wang et al. (2003), is $25 \%$. This error can be attributed to the analytical model by Wang et al. is proposed for long fracture slot (Wang et al., 2003). Using the analytical model for smaller fracture overestimates the equilibrium height. Thus, an overall good match 
of the simulation result with the experiment suggests that the simulation model can be used to

\section{Table 2}

448 Simulation parameters for comparison with the experimental results

\begin{tabular}{|l|l|}
\hline Fracture dimensions, $\mathrm{L} \times \mathrm{W} \times \mathrm{H}(\mathrm{m})$ & $0.381 \times 0.0762 \times 0.002$ \\
\hline Proppant diameter & $20 / 40$ sand \\
\hline Proppant density $\left(\mathrm{kg} / \mathrm{m}^{3}\right)$ & 2650 \\
\hline Fluid density $\left(\mathrm{kg} / \mathrm{m}^{3}\right)$ & 1000 \\
\hline Fluid inlet velocity $(\mathrm{m} / \mathrm{s})$ & $0.1,0.2,0.3$ \\
\hline Fluid viscosity (cP) & 1 \\
\hline Proppant volume fraction & $0.038,0.019,0.013$ \\
\hline Injection time (s) & 20 \\
\hline
\end{tabular}

Experimental results, Tong and Mohanty (2016) $\mathrm{v}=0.1 \mathrm{~m} / \mathrm{s}$

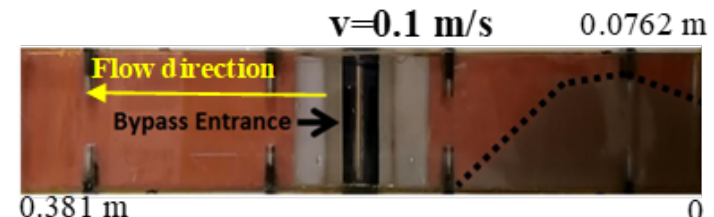

$0.381 \mathrm{~m}$

$\mathrm{v}=0.2 \mathrm{~m} / \mathrm{s}$

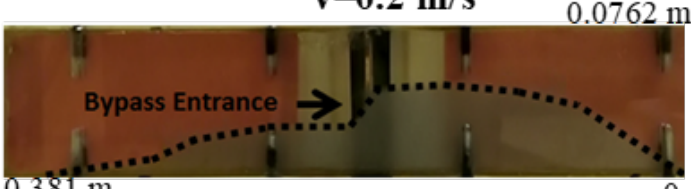

$\mathrm{v}=0.3 \mathrm{~m} / \mathrm{s}$

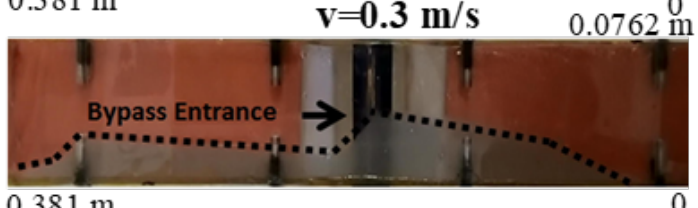

$0.381 \mathrm{~m}$
Simulation results from the Current

Model

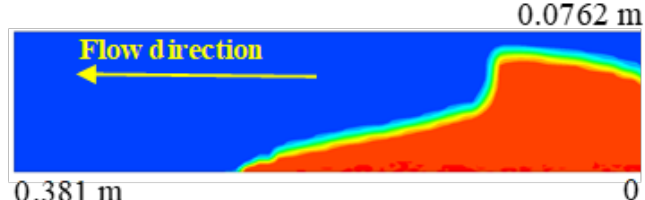

$0.381 \mathrm{~m}$ 0.0762

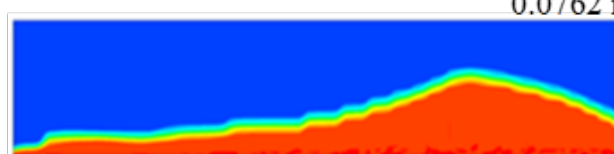

$0.0762 \mathrm{~m}$

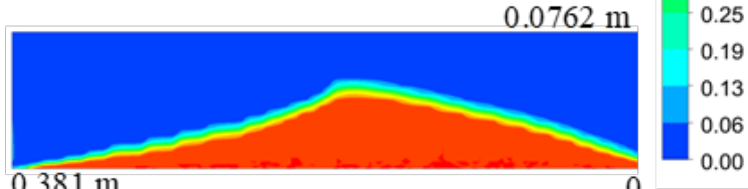

Fig. 6 Comparison of simulation results with experimental results at $\mathrm{t}=20 \mathrm{~s}$ 
玉 Experimental study (Tong and Mohanty, 2016)

를 Current Numerical Study

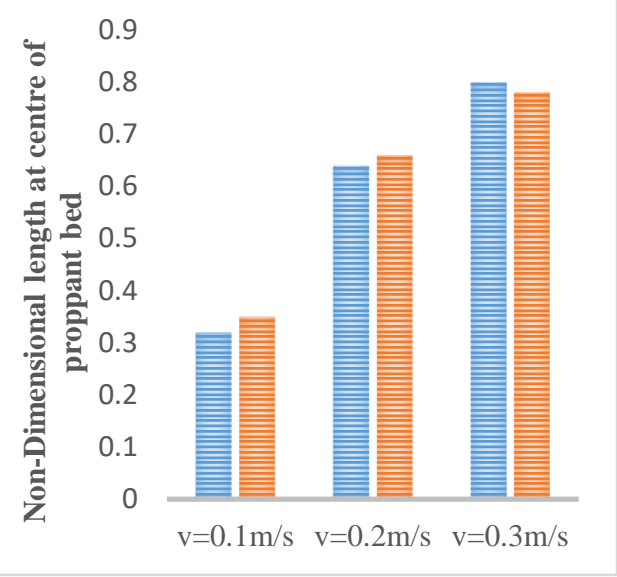

Е Experimental study (Tong and Mohanty, 2016)

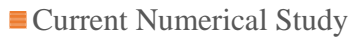

르 Wang et al. (2003) analytical model

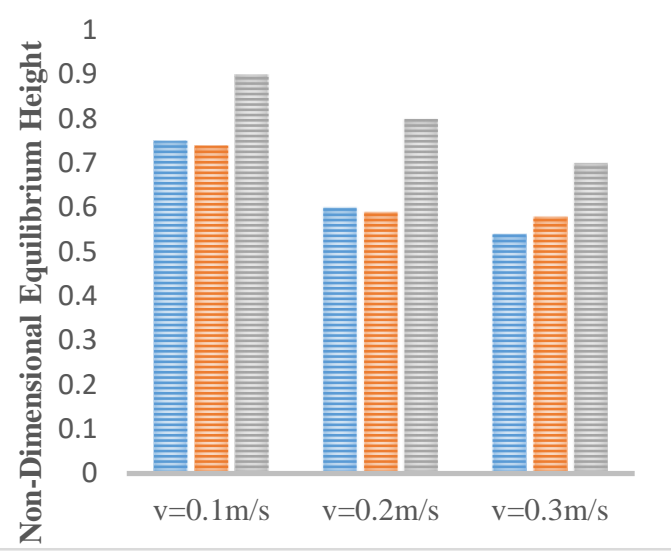

Fig. 7 Quantitative validation (a) comparison of non-dimensional proppant bed length for experimental study vs current numerical study (b) comparison of non-dimensional proppant bed height for the experimental study vs current numerical study

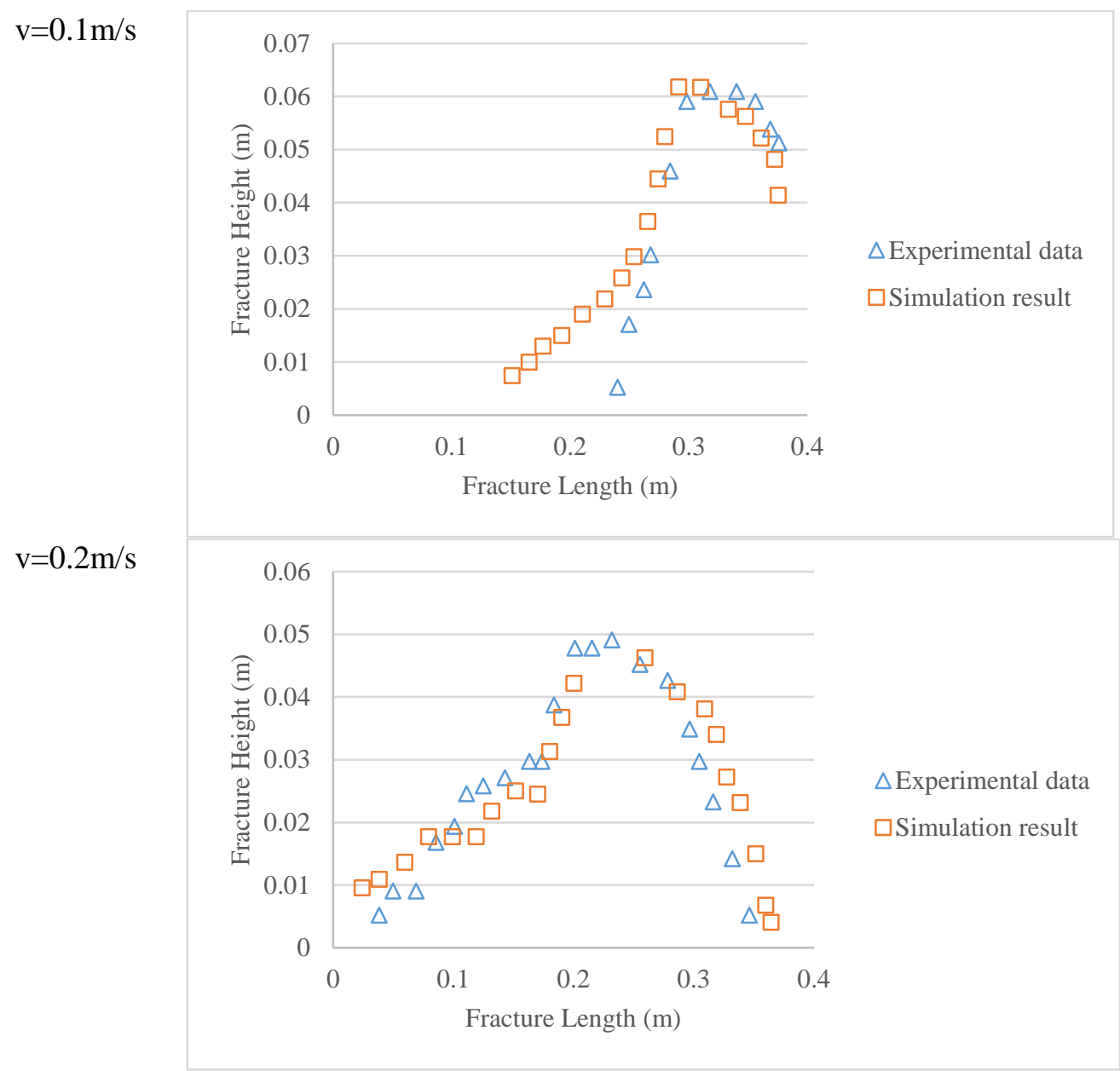




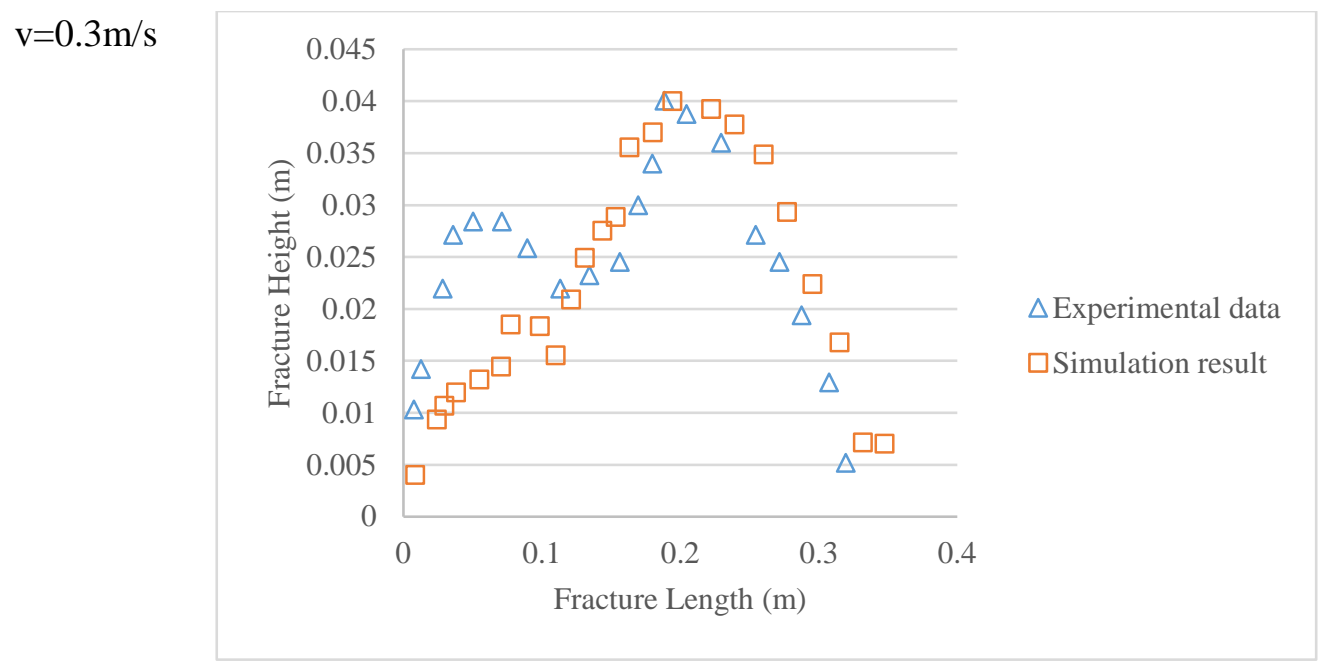

Fig. 8 Comparison of experimental data and numerical result at $\mathrm{t}=20 \mathrm{~s}$

\subsection{Effect of Fracture Roughness}

An investigation was carried out to understand the role of fracture wall roughness in proppant distribution. A comparison is made between the rough fracture case described in the geometry section earlier with the smooth fracture case with no fracture roughness. Fig. 9 and Fig. 10 shows the contour plot of proppant volume fraction for both the cases and their comparison respectively. It can be interpreted from Fig. 10 that, the fracture wall roughness provides additional drag resistance force near the fracture wall and thus, it resulted in shorter proppant bed length compared with the smooth wall fracture. Conversely, neglecting the fracture roughness in the proppant transport model can result in over predicting the proppant bed length. The proppant volume fraction was plotted with the non-dimensional fracture height at two vertical cross-sectional planes at $0.2 \mathrm{~m}$ and $1.4 \mathrm{~m}$ from the inlet in the longitudinal direction (Fig. 11). The results show that, away from the wellbore, in the case with fracture roughness, greater proppant particles in suspension is noticed compared with the smooth wall fracture case. This can be explained by the fracture roughness causes more turbulence in the flow and the increase in turbulence results in a more significant amount of proppants in the suspension region. The smooth fracture can be underpredicting the proppant transport by $10-15 \%$ in the proppant suspension layer.

In order to investigate in detail, the role of turbulence caused by the rough fracture surfaces on the flow field and proppant transport, a comparison of vorticity, velocity vector and turbulent kinetic energy was made between rough fracture and smooth fracture cases in Fig. 12. It is noticed that the rough fracture surface induces a high vortex region resulting in higher turbulence (Fig. 12a). This can further be supported by the high turbulent kinetic energy observed in the especially near the fracture wall, that aids in the greater suspension of the proppants in the fracturing fluid (Fig. 12c). Fig. 12b shows the zoomed view of the velocity vector field of the continuous phase at the fracture wall, and it can be noticed that the including the fracture roughness into the model disrupts the continuous velocity vector field in the smooth fracture wall case into vortices in the rough fracture wall case that can significantly affect the proppant transport and distribution. Thus, the comparison results explain that inclusion of the fracture roughness in the proppant transport model is vital in proppant distribution study, and assuming the fracture wall as smooth can underpredict the proppant transport in the proppant suspension layer and overpredict the proppant bed length. 


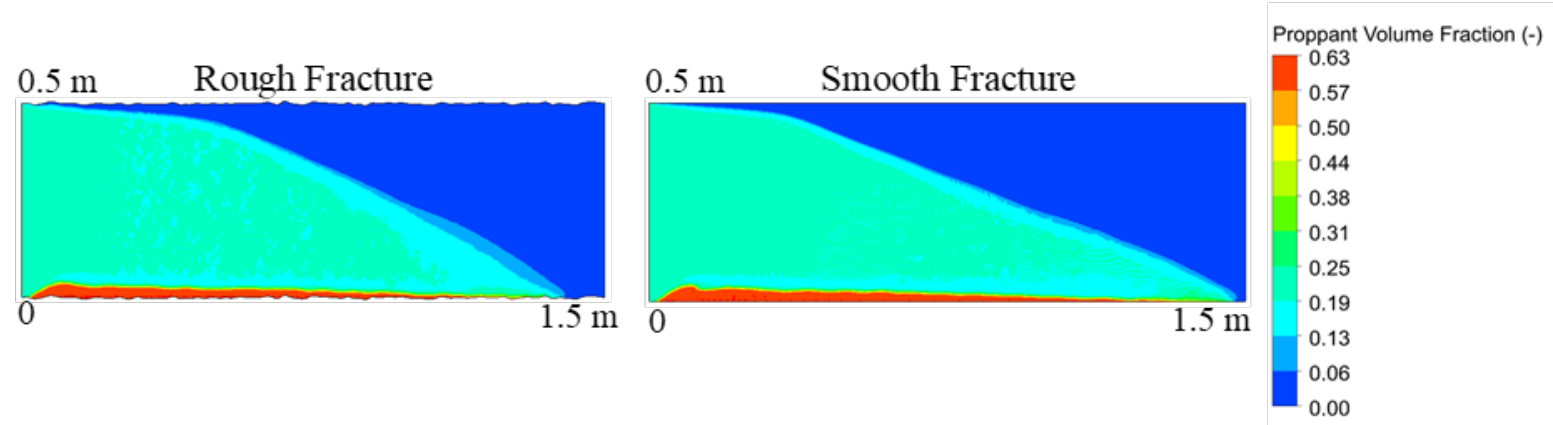

498

499

500

501

502

503

Fig. 10 Comparison of rough and smooth fracture cases at $t=2 \mathrm{~s}$

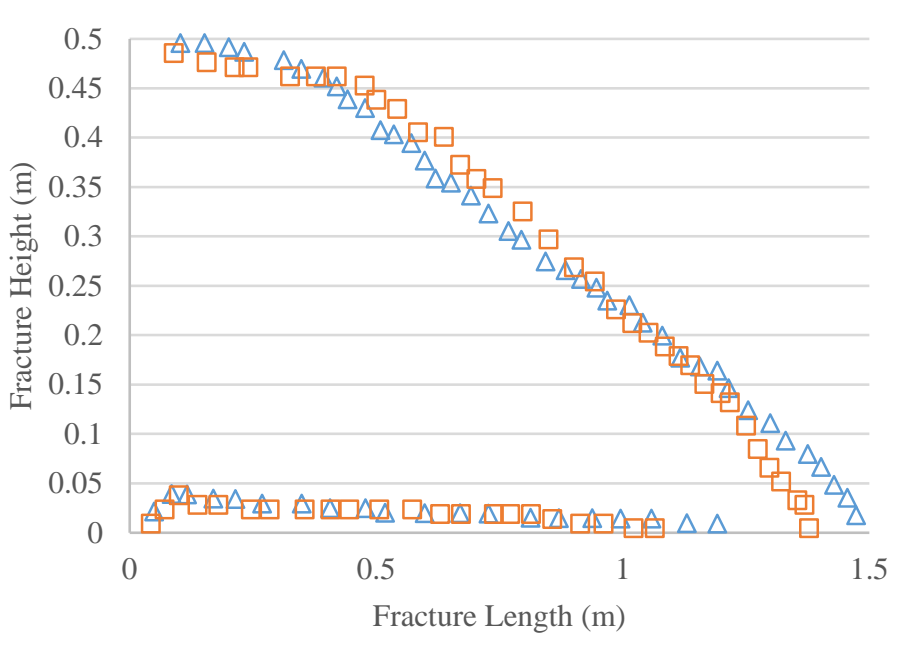

$\triangle$ Smooth Fracture

$\square$ Rough Fracture
@ $\mathrm{x}=0.2 \mathrm{~m}$ from inlet

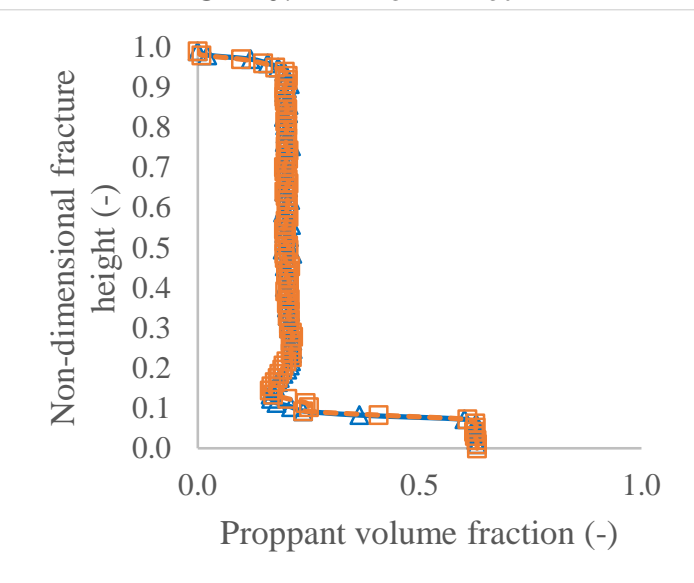

Legend
@ $\mathrm{x}=1.4 \mathrm{~m}$ from inlet

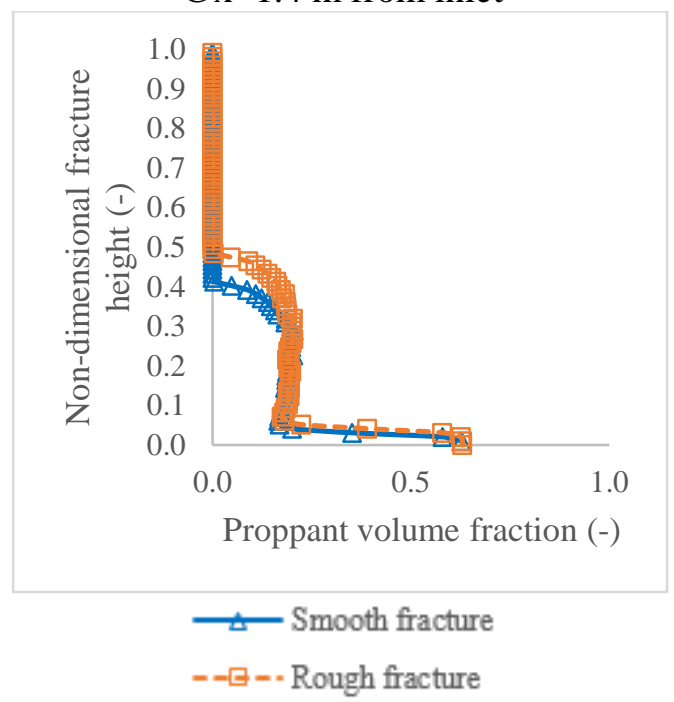

Fig. 11 Comparison of the proppant volume fraction with the non-dimensional fracture height at for smooth and rough fracture case $\mathrm{t}=3 \mathrm{~s}$ 
Legend

(a) Vorticity

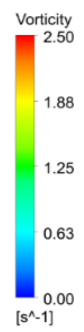

(b) Velocity vector plot
Smooth fracture
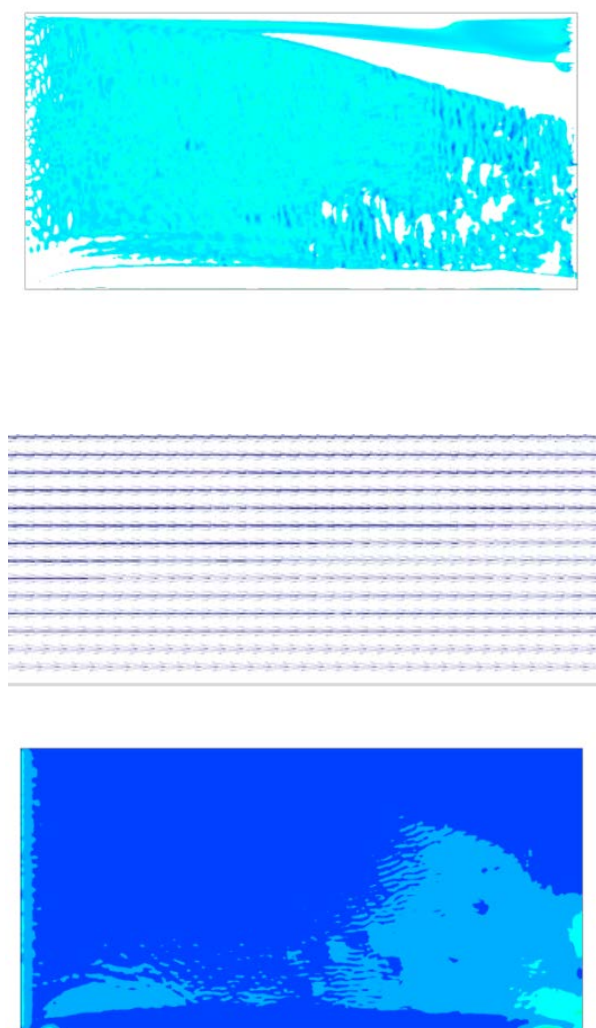

Rough fracture
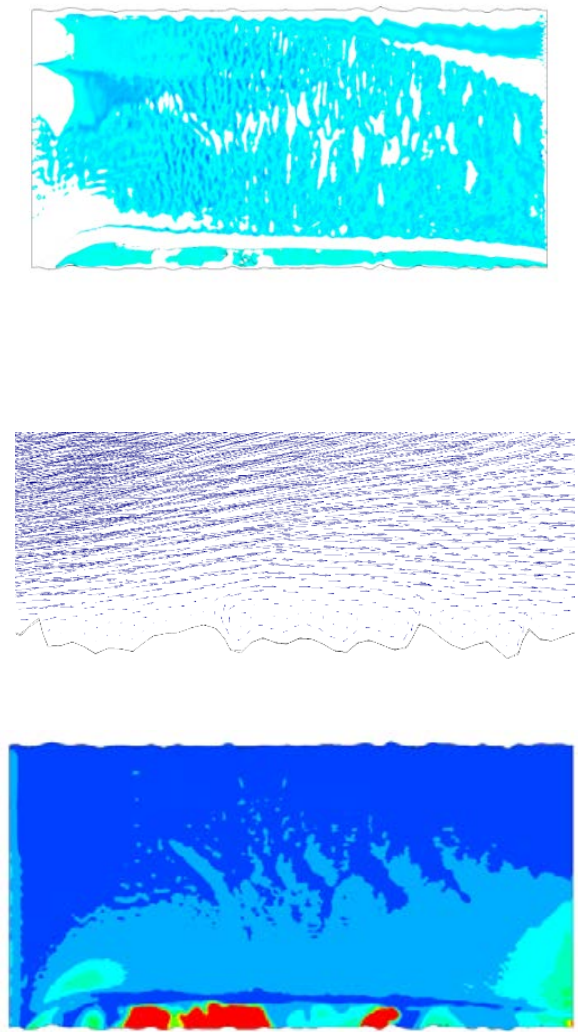

507 (c) Turbulence kinetic energy

Turbulence Kinetic Energy
0.14
0.13
0.11
0.10
0.08
0.07
0.06
0.04
0.03
0.01
0.00
$\left[m^{\wedge} 25^{\wedge}-2\right]$

Fig. 12 Comparison of vorticity, velocity vector and turbulence kinetic energy plots for smooth vs rough fracture case

\subsection{Effect of the fluid leak-off rate at fracture wall}

Next, an analysis was carried out to understand the effect of fluid leak-off at the fracture wall on proppant distribution. A comparison is made between the fluid leak-off from the fracture wall and neglecting the fluid leak-off, as shown in Fig. 13. The proppant volume fraction was plotted with the fracture height at $\mathrm{t}=2.5 \mathrm{~s}$ after the start of injection at two vertical crosssectional planes at $0.2 \mathrm{~m}$ and $1.4 \mathrm{~m}$ from the inlet in the longitudinal direction (Fig. 13). The results show that neglecting the fluid leak-off phenomenon at the fracture wall in the proppant transport study can have a significant impact on the proppant distribution inside the fracture. As the fluid leaks off the fracture wall, the proppants tends to deposit at the fracture bottom and thus greater proppant bed height is noticed in fluid leak-off case compared with the no leak-off case. Neglecting the leak off effects can result in under predicting the proppant bed height by $10-50 \%$ and over predicting the suspension layer by $10-50 \%$. 
$@ \mathrm{x}=0.2 \mathrm{~m}$ from inlet

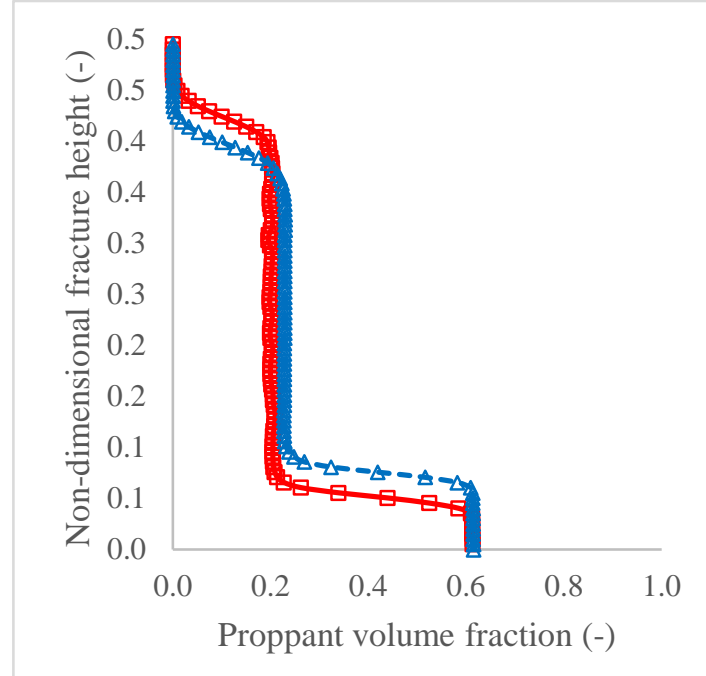

Legend @x=1.4 m from inlet

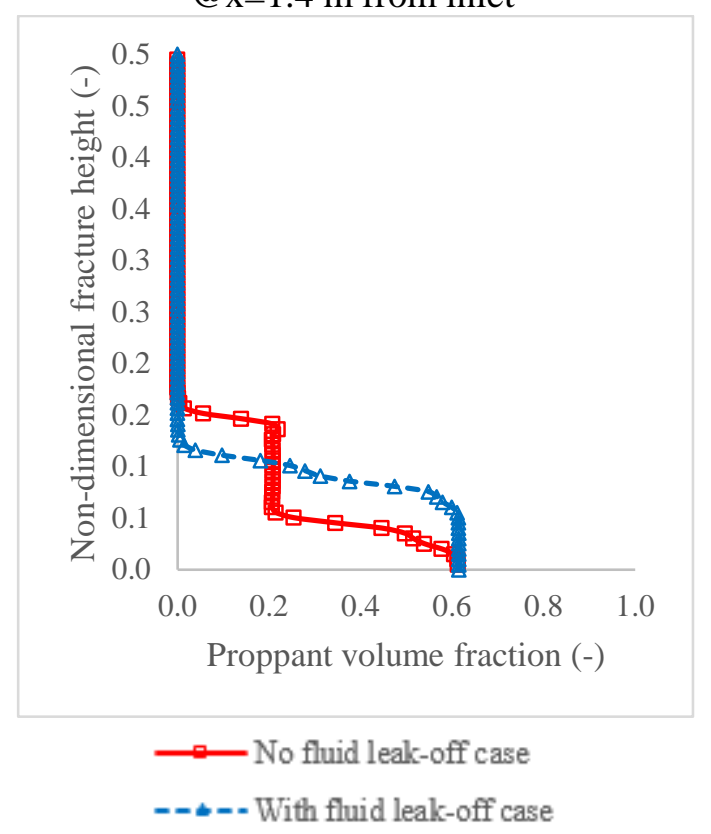

Fig. 13 Comparison of Fluid Leak-off case with no leak-off from the fracture wall at $2.5 \mathrm{~s}$

\subsection{Effect of injection velocity}

The injection velocity was varied, keeping all the other parameters constant, and simulation run was performed. The three cases of variation in injection velocity studied are $\mathrm{v}=0.1 \mathrm{~m} / \mathrm{s}, 0.5$ $\mathrm{m} / \mathrm{s}$ and $1 \mathrm{~m} / \mathrm{s}$. Fig. 14 is the contour plots of proppant volume fraction at fracture mid-plane for different time step and all the three cases of variation in injection velocity. It shows the difference in proppant distribution inside the fracture with time. It can be interpreted from the contour plots that as the injection velocity is increased, it results in a greater proppant deposition away from the wellbore. The higher amount of proppant is in the suspension layer with the increase of injection velocity and results in proppant being transported longer.

Next, to analyse the proppant bed height, comparing the case of v=0.5 m/s @2 s and v=1 m/s @1 s shows that increasing the injection velocity results in a reduction in proppant bed height. The proppants tend to suspend and are transported further. Similar observation is also seen comparing case of v=0.1 m/s @3 s and v=0.5 m/s @1 s.

To quantitatively understand these results, two vertical cross-sectional planes were selected at $0.2 \mathrm{~m}$ and $1.4 \mathrm{~m}$ from the inlet in the longitudinal direction (Fig. 15). The proppant volume fraction and proppant axial velocity were plotted with the non-dimensional fracture height at these planes and the advancement of proppant volume fraction and proppant axial velocity with time was analysed (Fig. 16 and Fig. 17). The results show that the increase in injection velocity provides greater energy for the proppant to remain in the suspension layer and as a result transport the proppants to the longer distance inside the fracture.

The parametric study of the proppant distribution to injection velocity suggests that it can play a significant role in optimising proppant distribution and hence the fracture conductivity. One practical approach, for low viscosity fluid like slickwater, could be injecting the proppant at higher injection rates to enhance the proppant transport in fractures. 


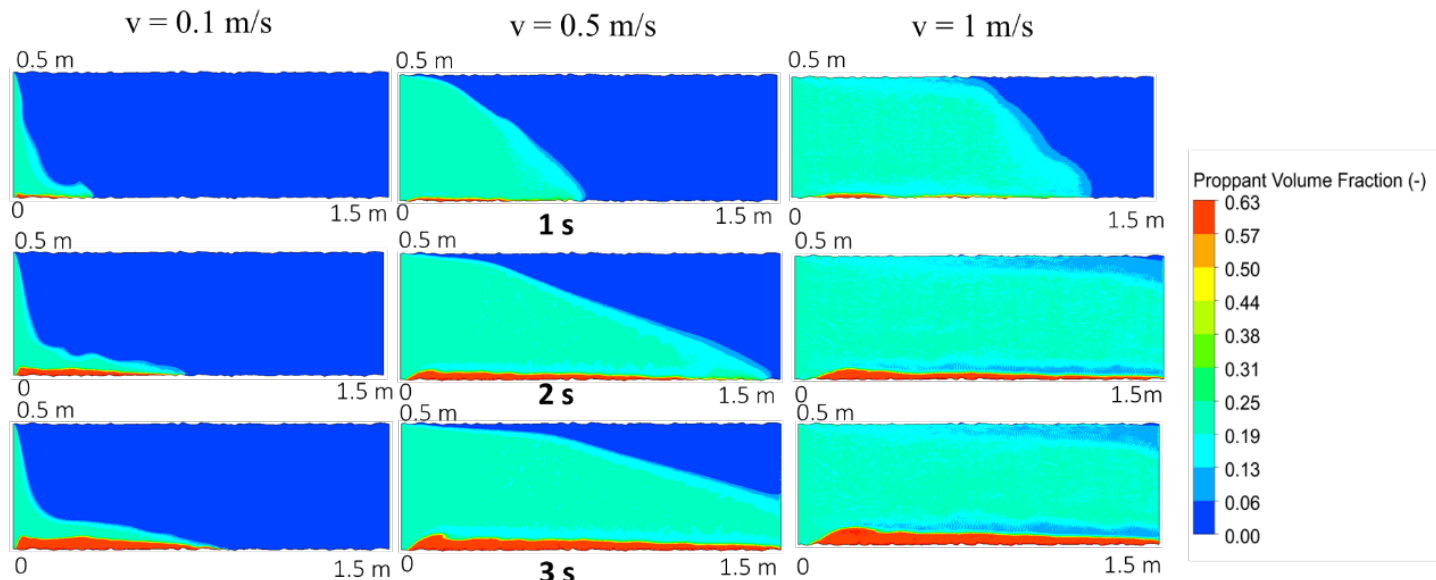

564 Fig. 14 Contour plot for proppant volume fraction at fracture mid-plane showing three cases of 565 variation in injection velocity $0.1 \mathrm{~m} / \mathrm{s}, 0.5 \mathrm{~m} / \mathrm{s}$ and $1 \mathrm{~m} / \mathrm{s}$

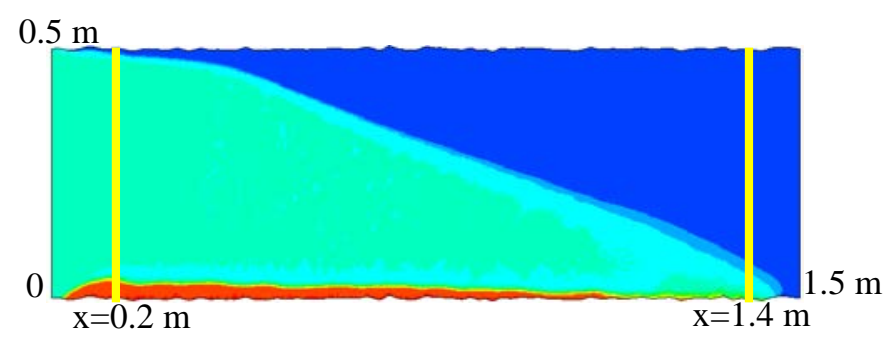

Fig. 15 Location of vertical planes at $\mathrm{x}=0.2 \mathrm{~m}$ and $\mathrm{x}=1.4 \mathrm{~m}$ from the inlet to quantitatively analyse the results
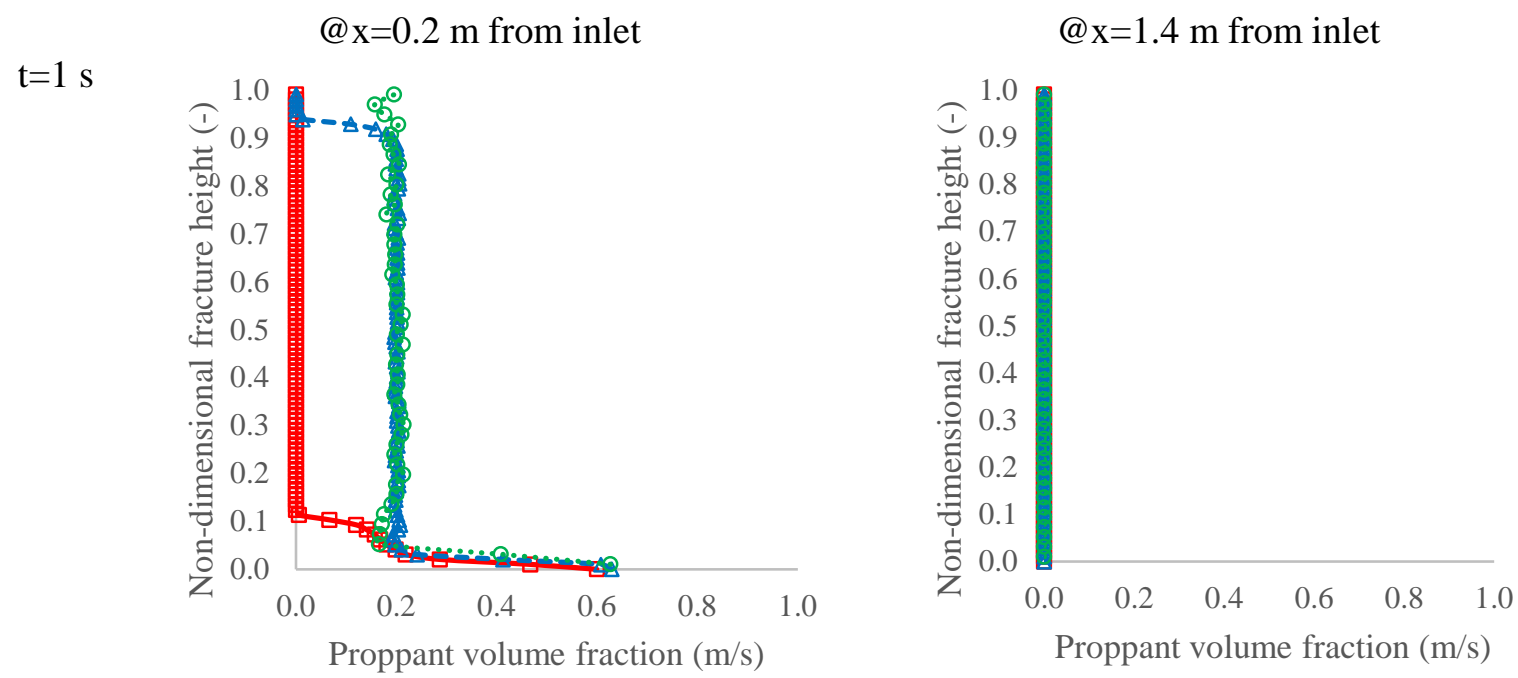

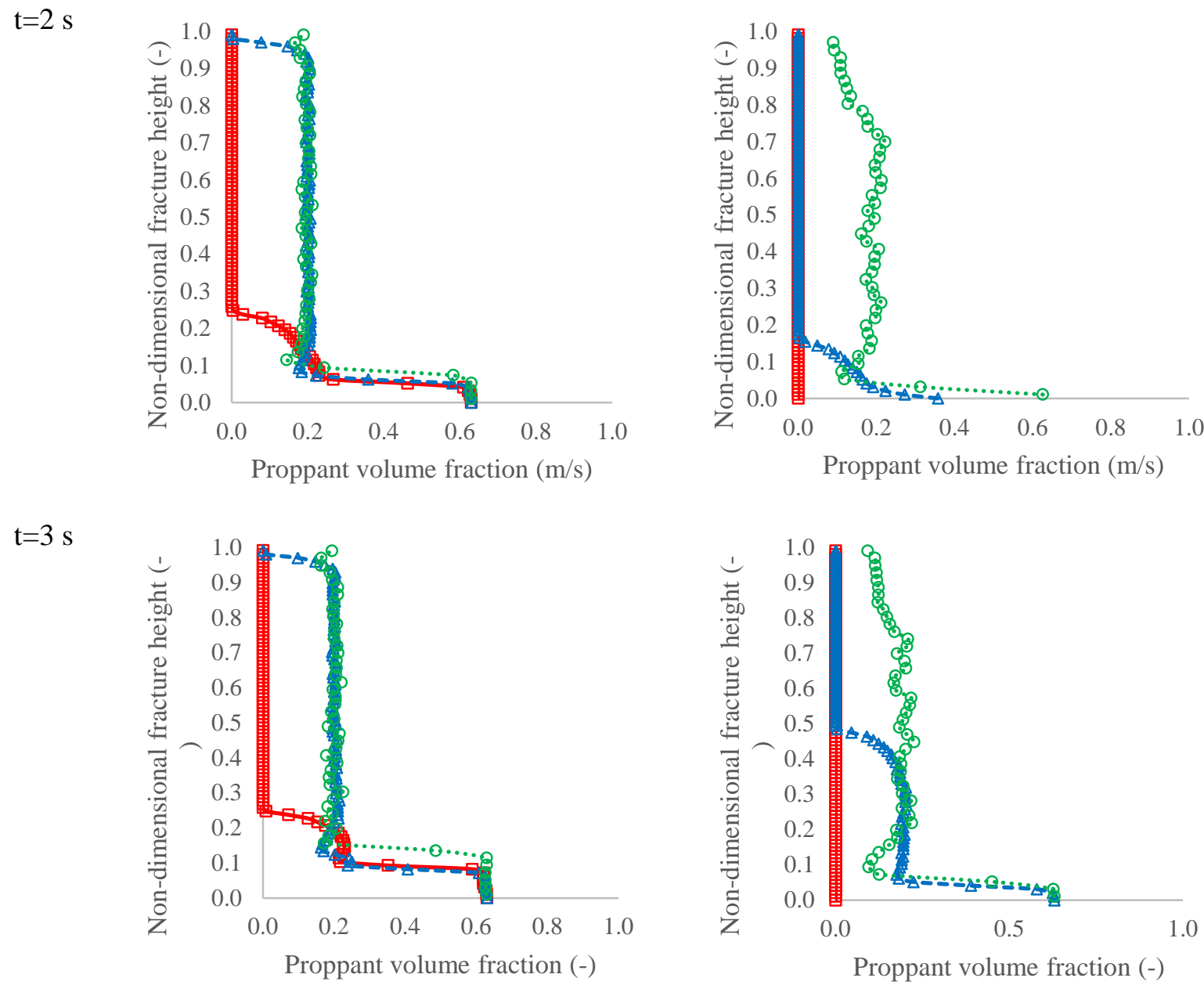

Fig. 16 Comparison of the proppant volume fraction with the non-dimensional fracture height

Legend

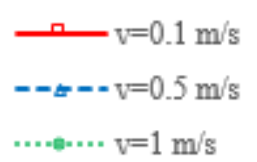
$\mathrm{m}$ ) inside the fracture

573

@ $\mathrm{x}=0.2 \mathrm{~m}$ from inlet

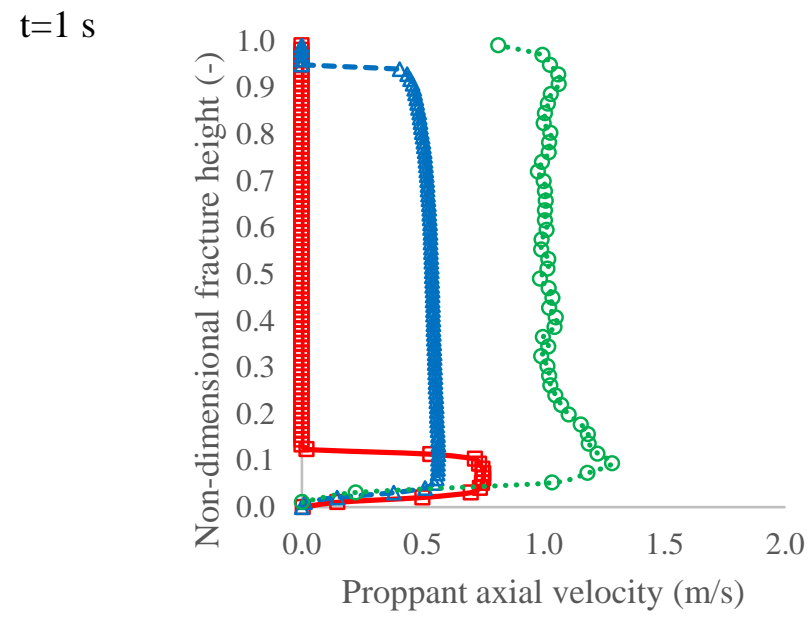

@x=1.4 m from inlet

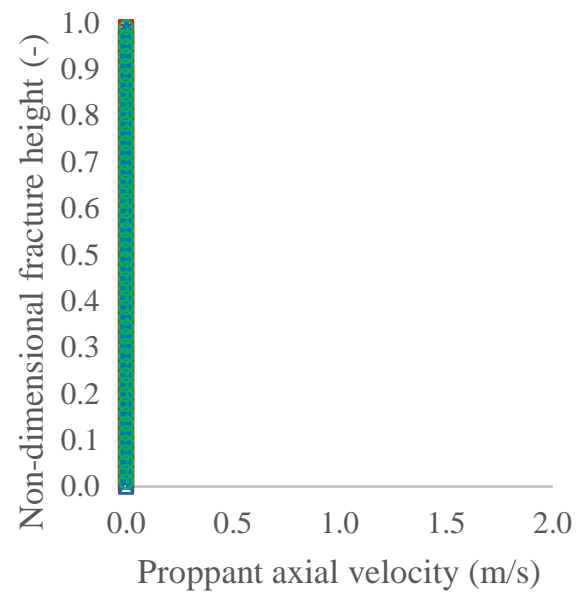



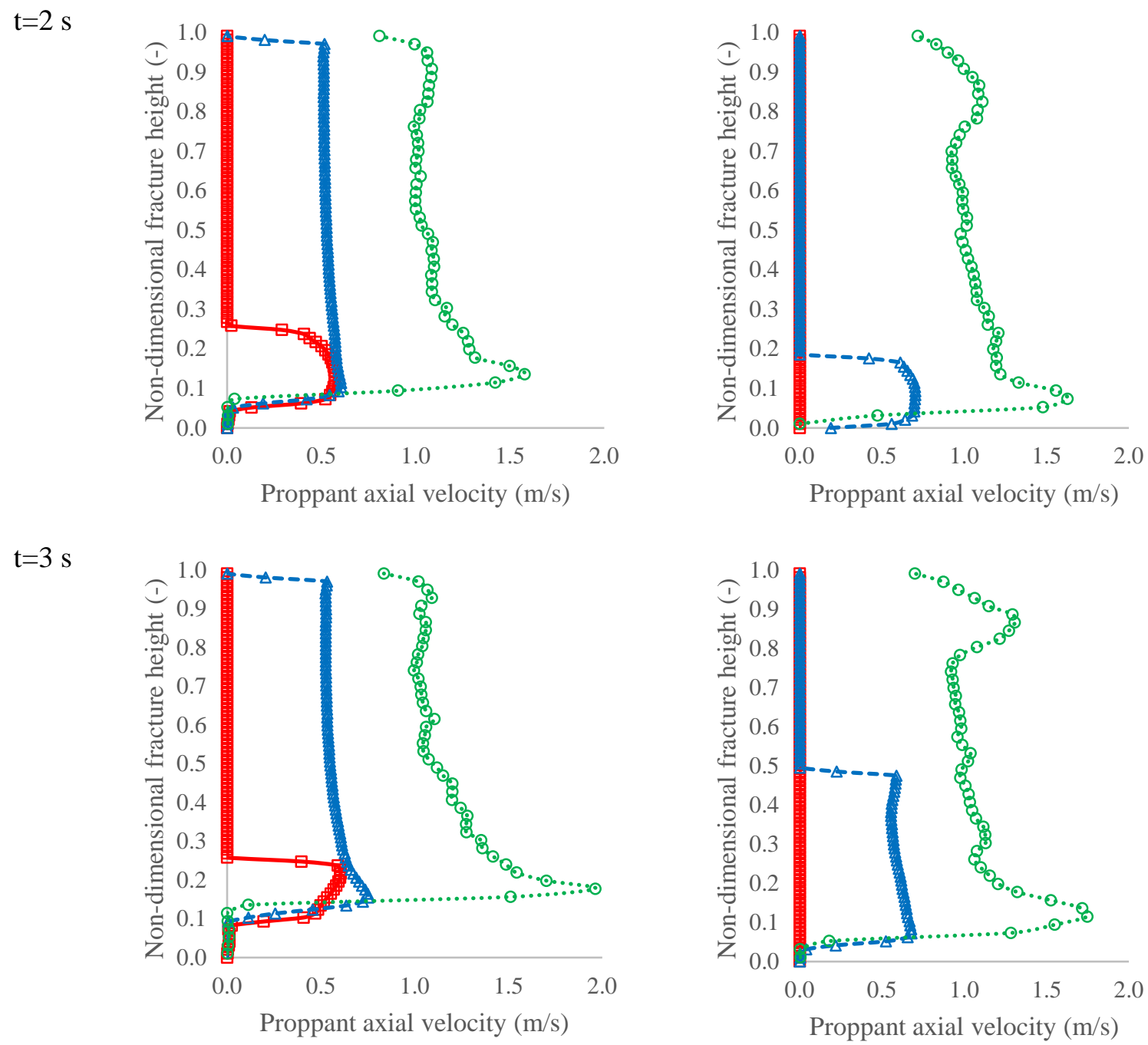

Legend

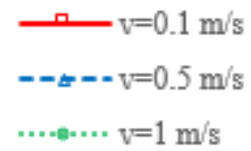

574

Fig. 17 Comparison of the proppant axial velocity with the non-dimensional fracture height for injection velocities $0.1 \mathrm{~m} / \mathrm{s}, 0.5 \mathrm{~m} / \mathrm{s}$ and $1 \mathrm{~m} / \mathrm{s}$ at two different locations ( $\mathrm{x}=0.2 \mathrm{~m}$ and $\mathrm{x}=1.4 \mathrm{~m}$ ) inside the fracture

\subsection{Effect of Proppant Concentration}

In the next study, the proppant concentration was varied keeping all the other parameters constant, and simulation run was performed. The three cases of variation in proppant concentration studied are $c=0.10,0.15$ and 0.20 . Fig. 18 is the contour plots of proppant volume fraction at fracture mid-plane for different time step showing all the three cases of variation in proppant volume fraction. It can be interpreted from the contour plots that the proppant concentration has a complex effect on proppant transport, such as proppant settling velocity, the rate of proppant bed build-up. The higher proppant concentration can help in transporting proppant to a longer distance and greater proppant bed height.

Next, the proppant volume fraction and proppant axial velocity was plotted with the fracture height and the advancement of proppant volume fraction with time at the two-different vertical planes was analysed (Fig. 19 and Fig. 20). The results show that the case with $c=0.20$ having higher proppant concentration tends to transport proppant to the longer distance (@x=1.4 m $\mathrm{t}=2 \mathrm{~s} ; \mathrm{t}=3 \mathrm{~s}$ ) which is the primary objective in the shale gas reservoirs and also has higher 
proppant velocity in the longitudinal direction. Often the significant challenge using slick water fracturing fluid in shale gas reservoir is quick deposition of proppants with shorter proppant bed length. This parametric study results in an important conclusion that the proppant transport, distribution and settling is substantially dependent on the proppant concentration. Higher proppant concentration can assist in achieving longer proppant bed length.

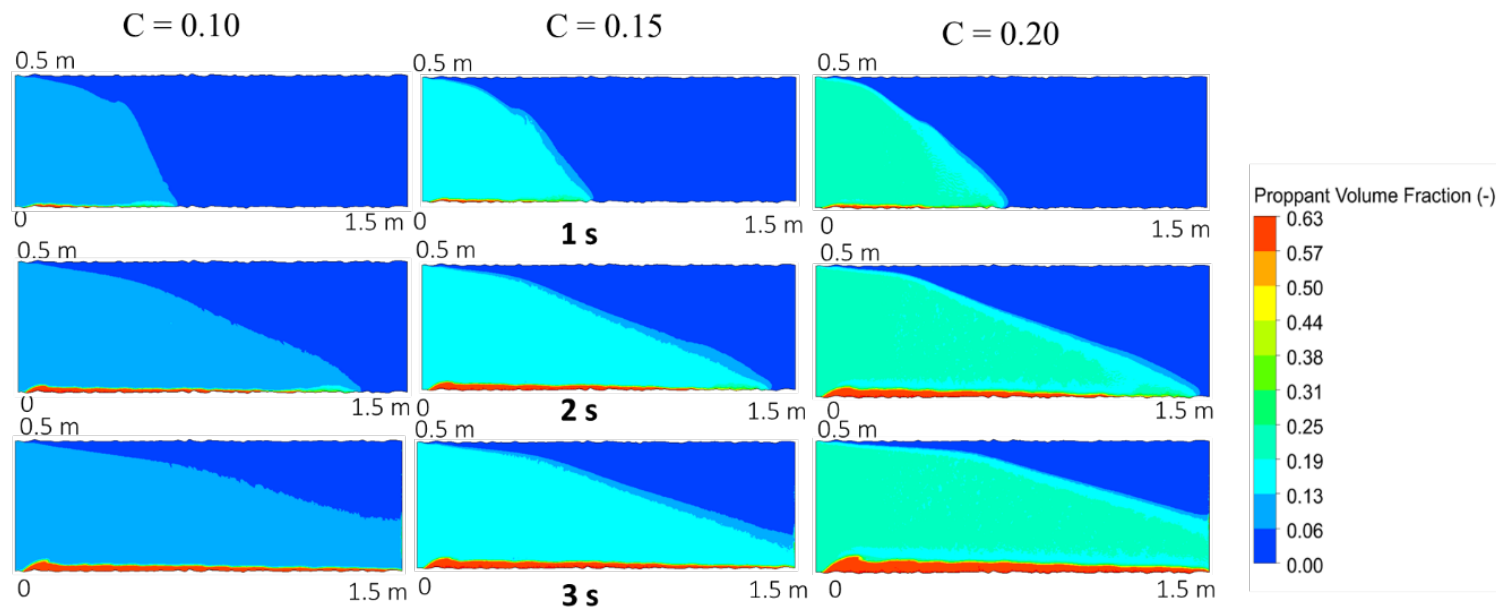

Fig. 18 Contour plot for proppant volume fraction at fracture mid-plane showing three cases of variation in proppant concentration $\mathrm{c}=0.10,0.15$ and 0.20

$\mathrm{t}=1 \mathrm{~s}$

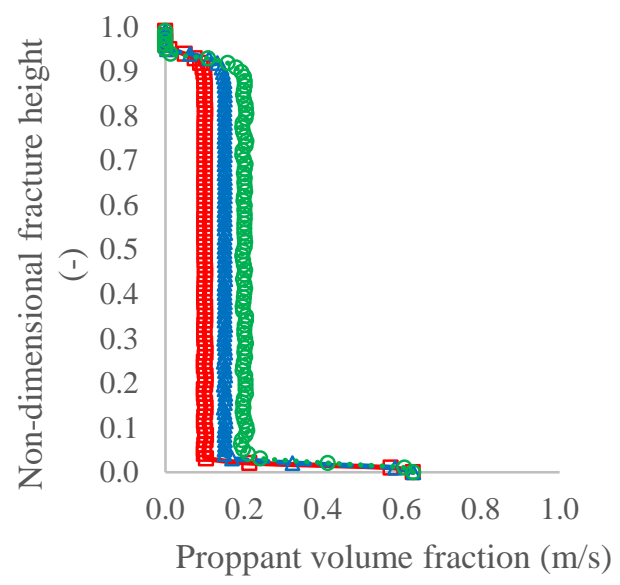

$t=2 s$

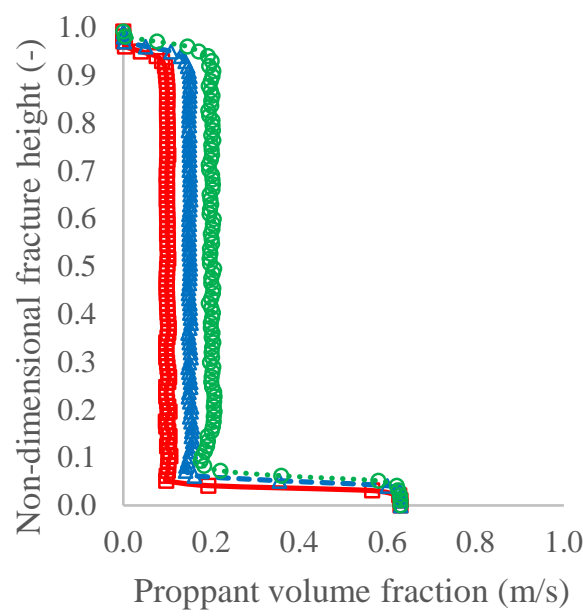

@x=1.4 m from inlet
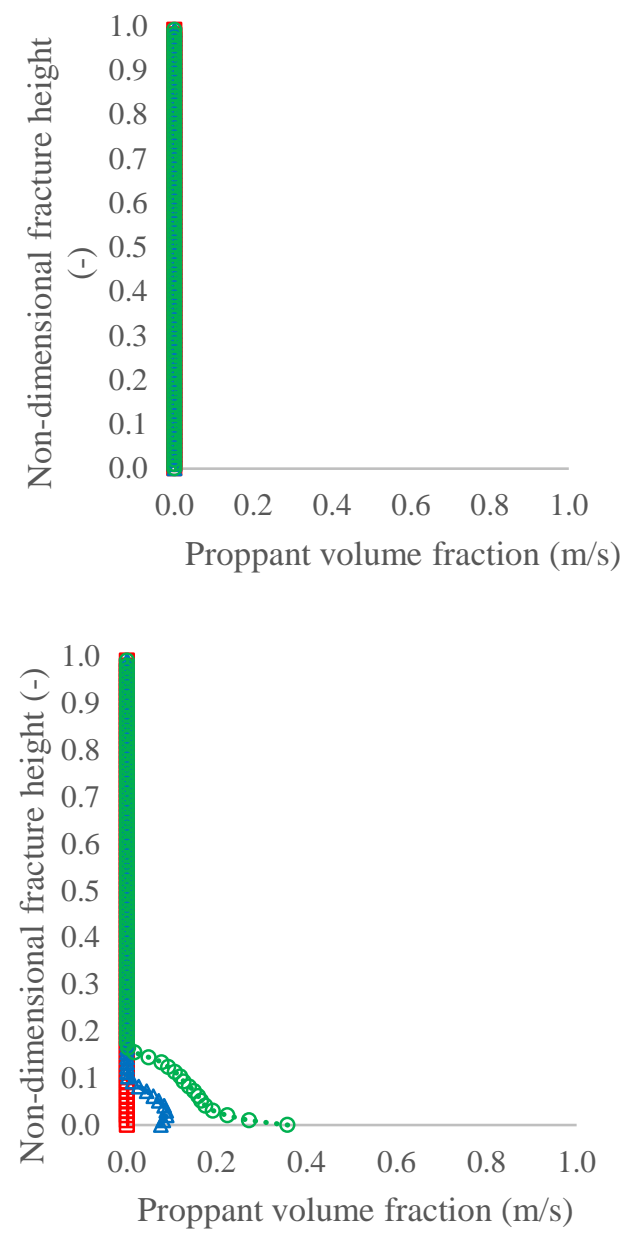


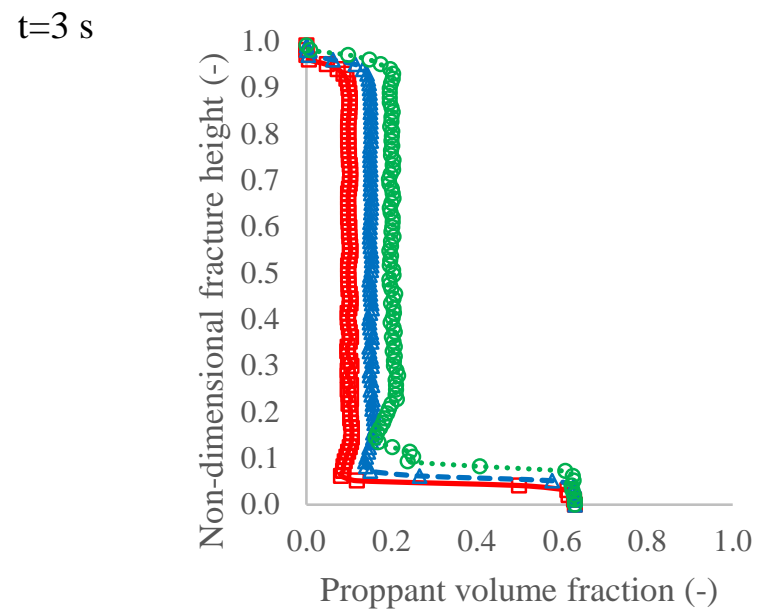

Legend
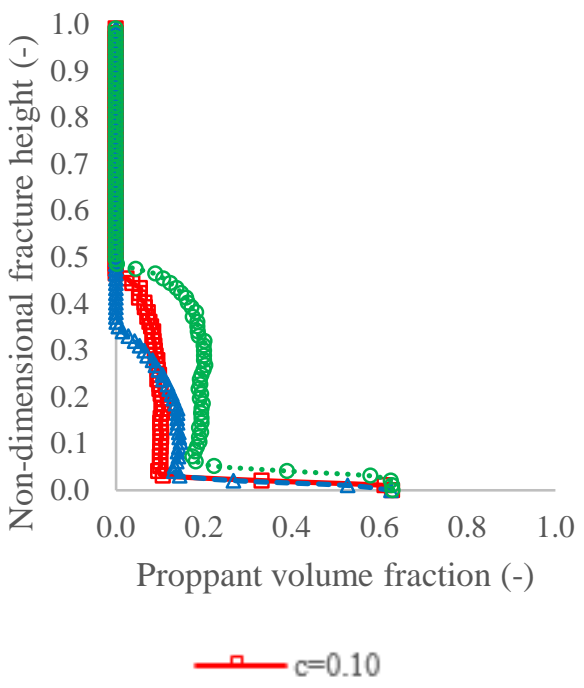

$--m-c=0.15$

602 Fig. 19 Comparison of the proppant volume fraction with the non-dimensional fracture height for variation in proppant concentration $\mathrm{c}=0.10,0.15$ and 0.20 at two different locations $(\mathrm{x}=0.2$ $\mathrm{m}$ and $\mathrm{x}=1.4 \mathrm{~m}$ ) inside the fracture

$\mathrm{t}=1 \mathrm{~s}$

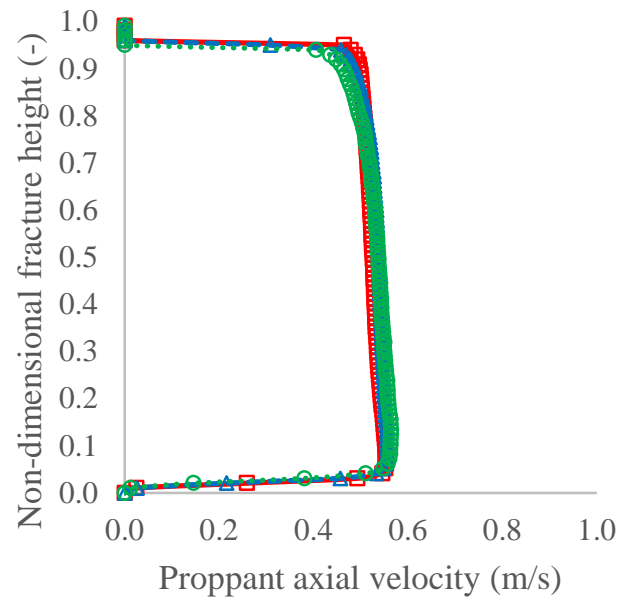

$\mathrm{t}=2 \mathrm{~s}$

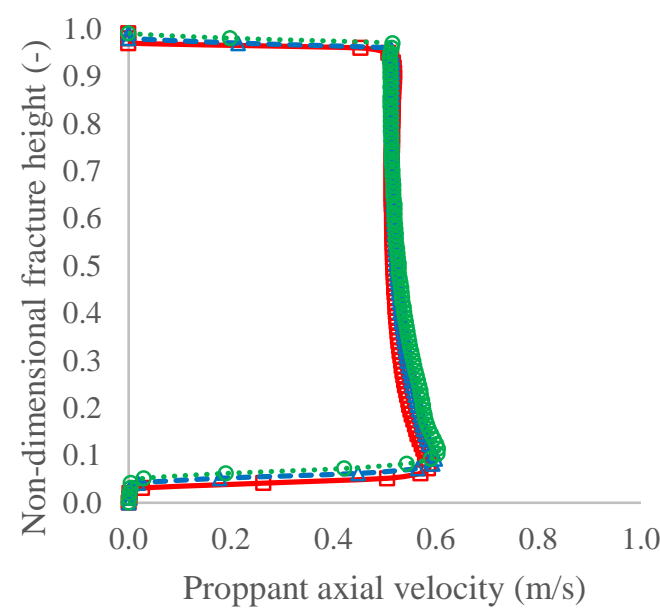

@x=1.4 m from inlet
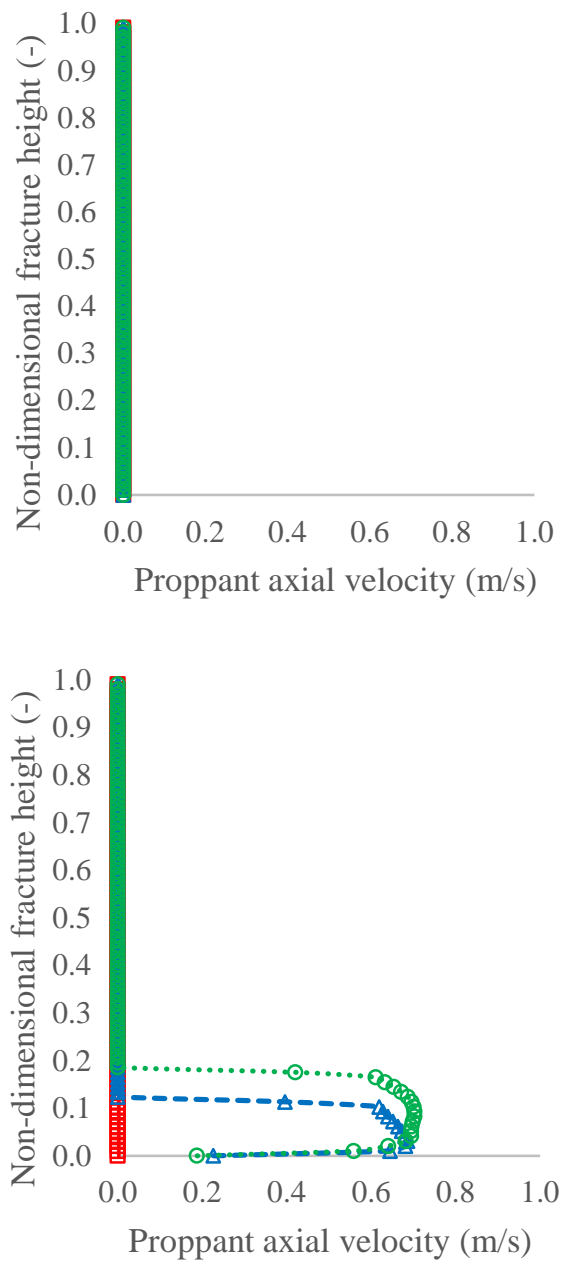


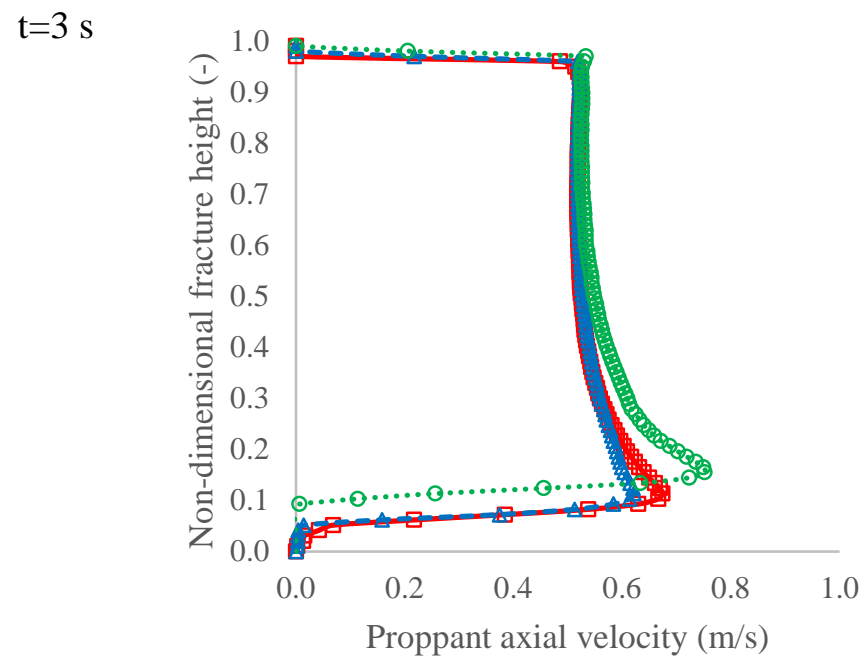

Legend
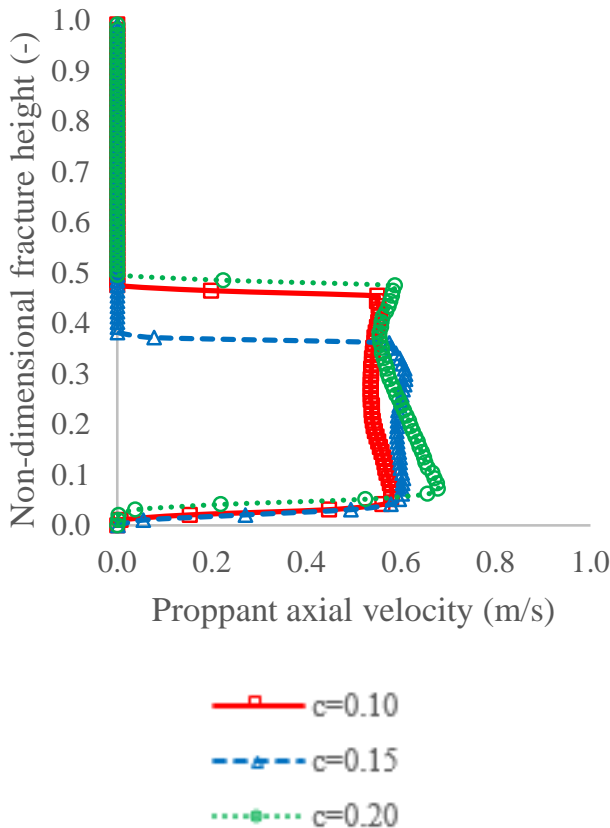

Fig. 20 Comparison of the proppant axial velocity with the non-dimensional fracture height for variation in proppant concentration $\mathrm{c}=0.10,0.15$ and 0.20 at two different locations $(\mathrm{x}=0.2 \mathrm{~m}$ and $\mathrm{x}=1.4 \mathrm{~m}$ ) inside the fracture

\subsection{Effect of fracture height}

In the next study, the fracture height was varied keeping all the other parameters constant, and simulation run was performed. The three cases of variation in fracture height studied are $h=0.2$ $\mathrm{m}, 0.5 \mathrm{~m}$ and $1 \mathrm{~m}$. Fig. 21 is the contour plots of proppant volume fraction at fracture mid-plane for different time step and shows all the three cases of variation in fracture height. The contour plot shows that the fracture height has a significant role in proppant transport. The higher fracture tends to suspend greater proppant in the slurry and transport proppants to a longer distance. To understand the results quantitatively, the proppant volume fraction was plotted with the normalised (dimensionless) fracture height and the time evolution of proppant volume fraction at the two-different vertical cross sections $\mathrm{x}=0.2 \mathrm{~m}$, and $\mathrm{x}=1.4 \mathrm{~m}$ from inlet was analysed (Fig. 22). Fig 22 shows that at time $=2 \mathrm{~s}$ and $3 \mathrm{~s}$, greater fracture height is helping to transport proppants to a greater distance by suspending more proppants. At $\mathrm{x}=0.2 \mathrm{~m}$, although lower proppant bed height is obtained for $\mathrm{H}=1 \mathrm{~m}$ case, the greater height can transport the proppant to longer length as evident at plane $\mathrm{x}=1.4 \mathrm{~m}$. Conversely, smaller fracture height results in greater proppant deposition. Comparing the proppant axial velocity (Fig. 23), it can be observed that away from the wellbore the proppants velocities are higher for the greater fracture height case, which is helping to have higher proppant bed length. This is significantly important for hydraulic fractures in the shale gas reservoirs. 
$\mathrm{H}=0.2 \mathrm{~m}$
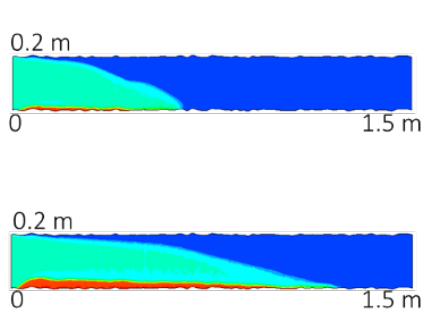

$0.2 \mathrm{~m}$

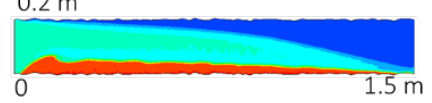

628 $0.5 \mathrm{~m}$ and $1 \mathrm{~m}$

Fig. 21 Contour plot of the proppant concentration for different fracture height cases $\mathrm{H}=0.2 \mathrm{~m}$,
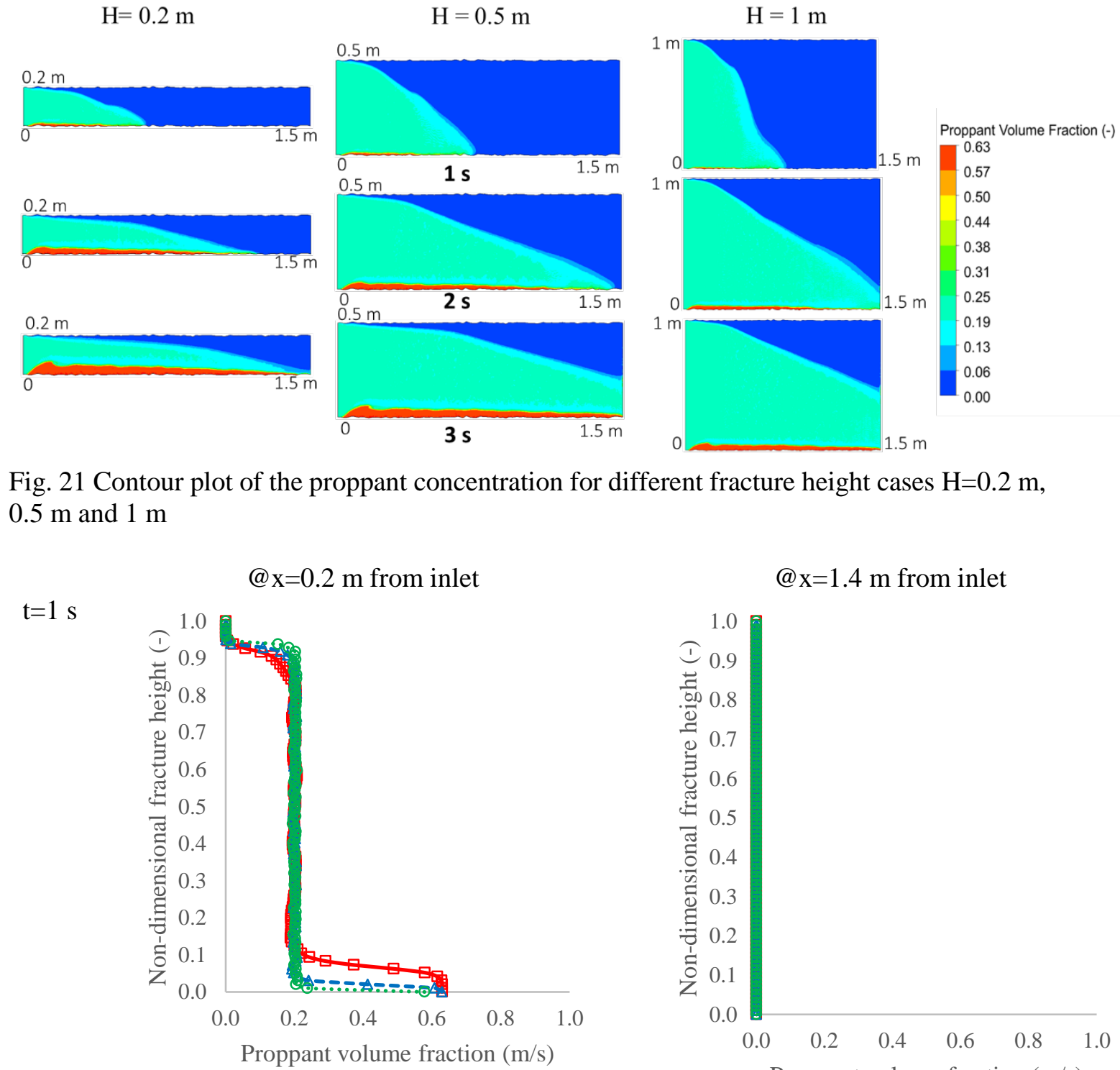

@ $\mathrm{x}=1.4 \mathrm{~m}$ from inlet

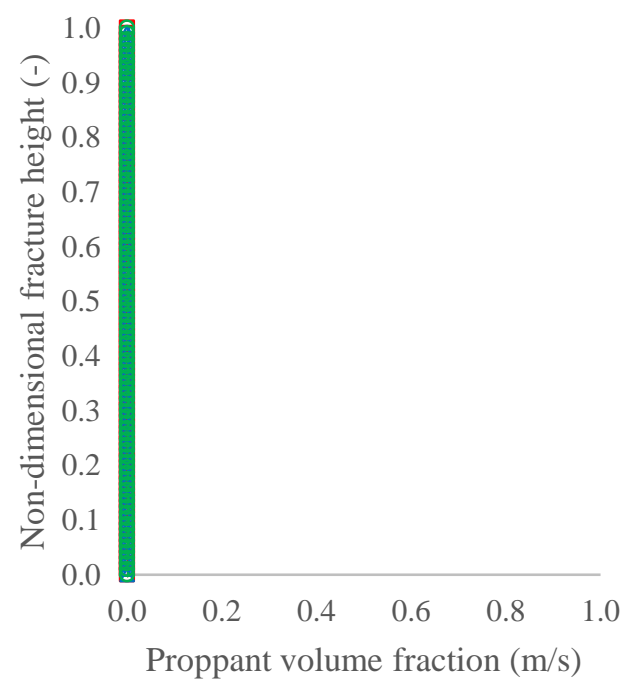

$\mathrm{t}=2 \mathrm{~s}$
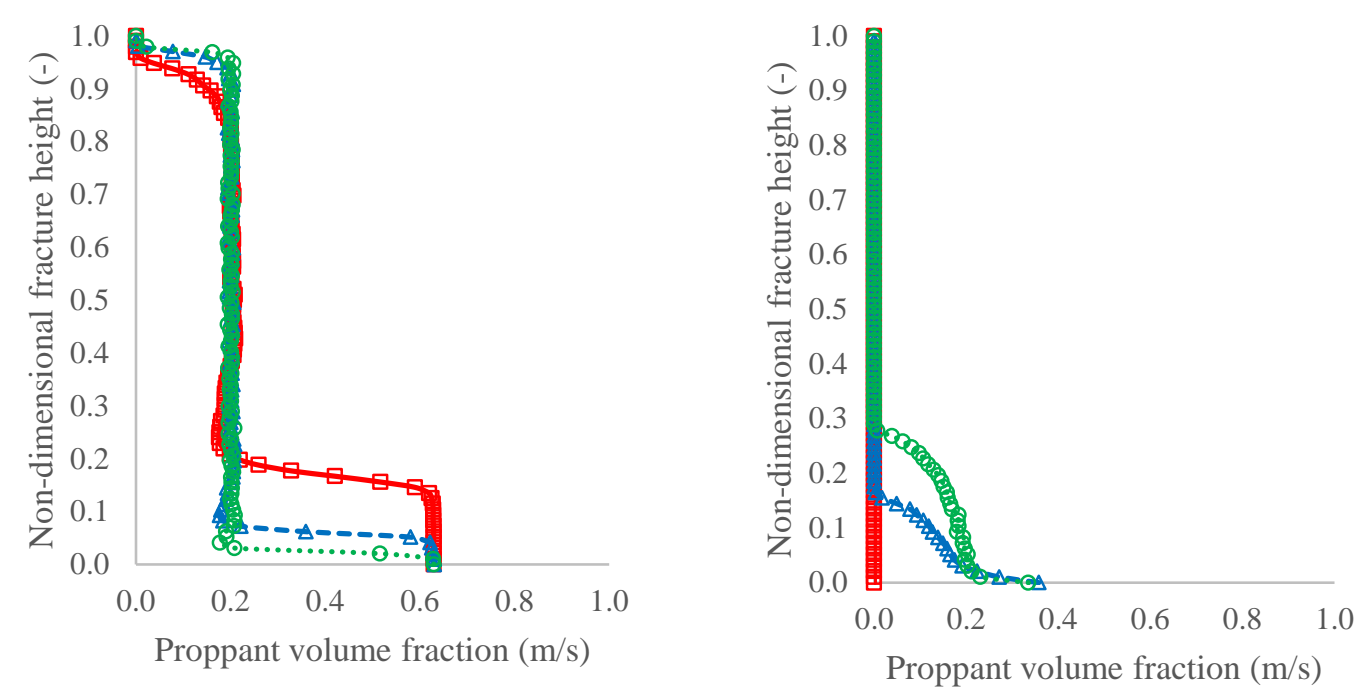

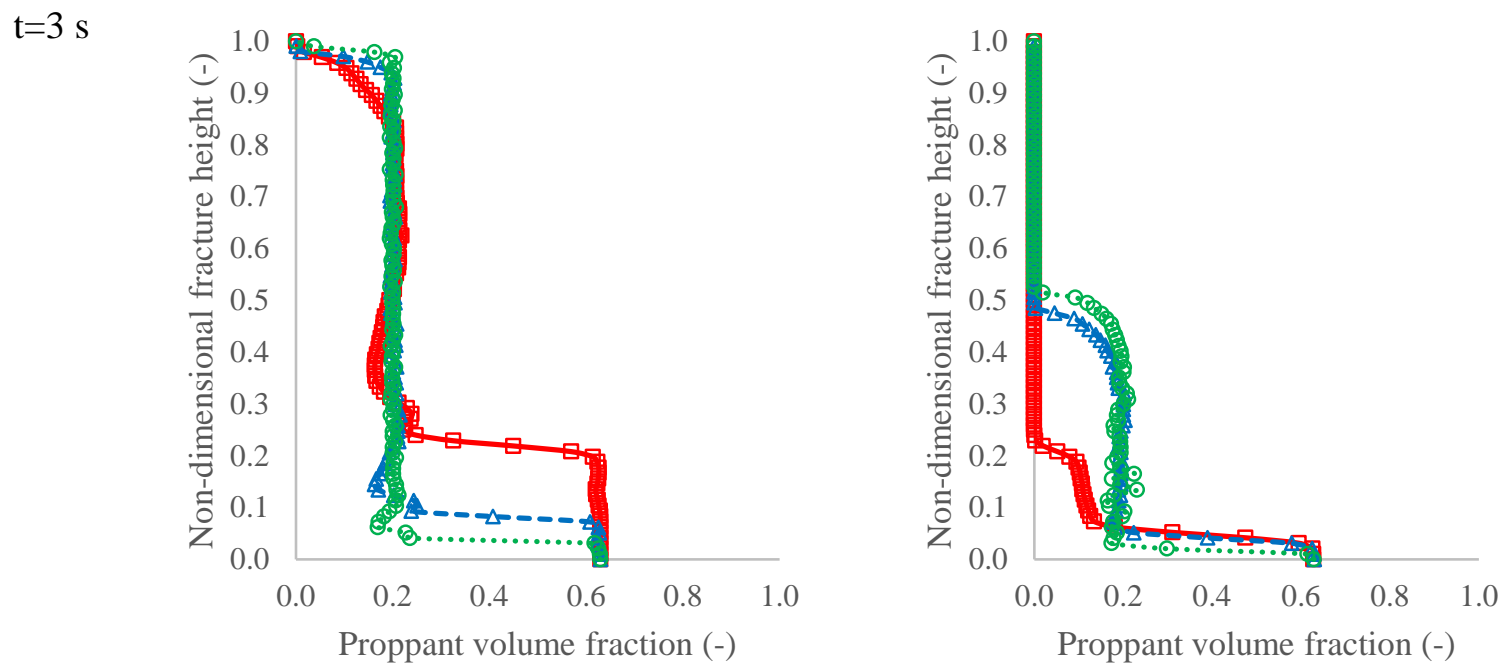

\section{Legend}

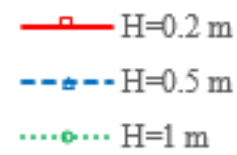

632 Fig. 22 Comparison of the proppant volume fraction with the non-dimensional fracture height for different fracture height cases $\mathrm{H}=0.2 \mathrm{~m}, 0.5 \mathrm{~m}$ and $1 \mathrm{~m}$ at two different locations ( $\mathrm{x}=0.2 \mathrm{~m}$ 634 and $\mathrm{x}=1.4 \mathrm{~m}$ ) inside the fracture

\section{5}

$\mathrm{t}=1 \mathrm{~s}$

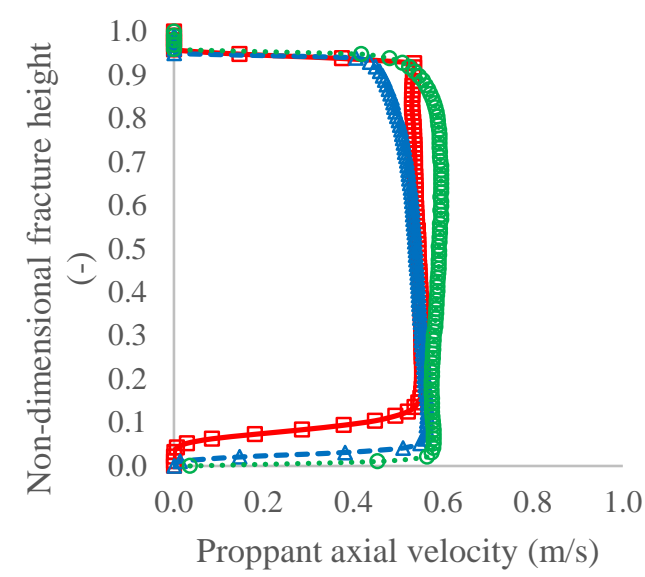

$t=2 s$

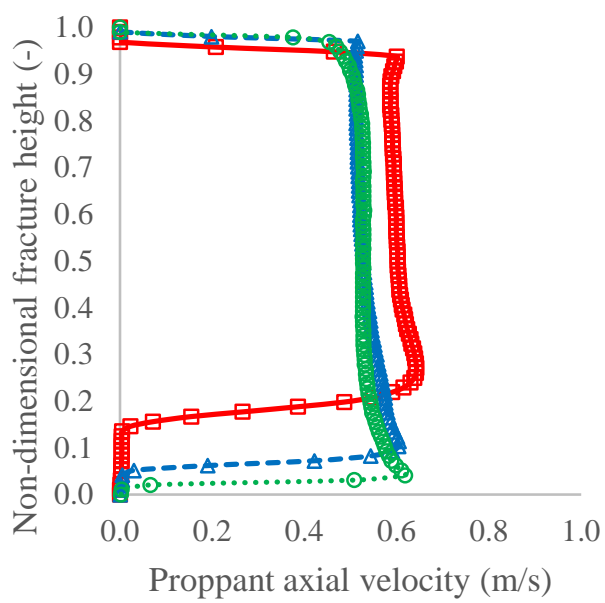

@x=1.4 m from inlet
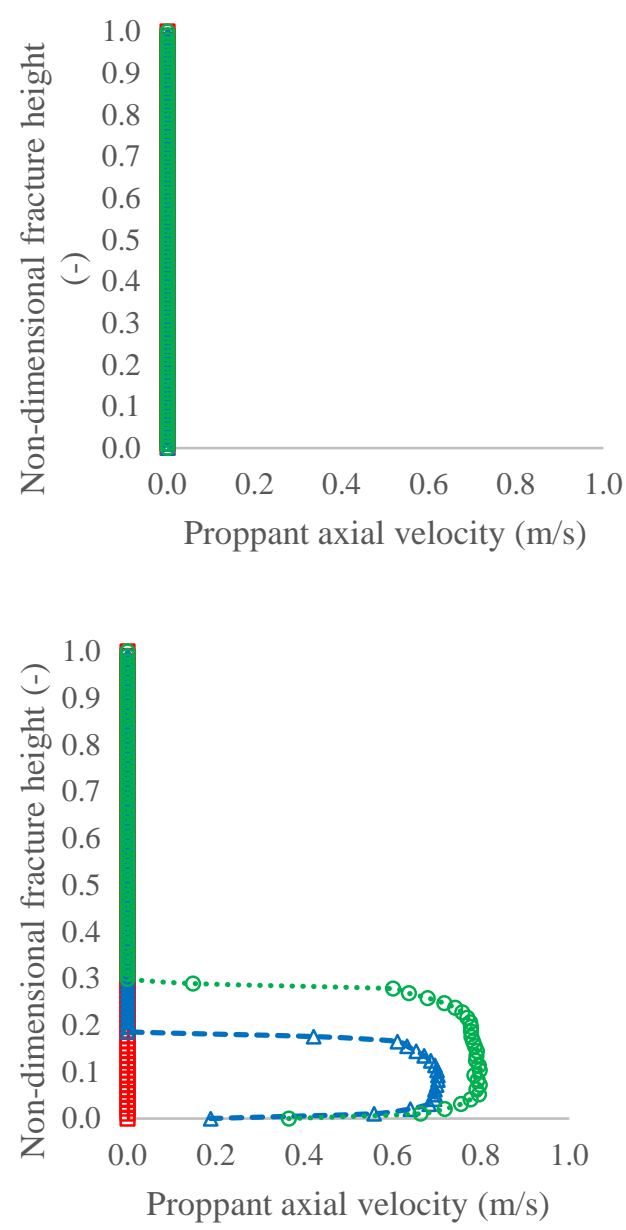


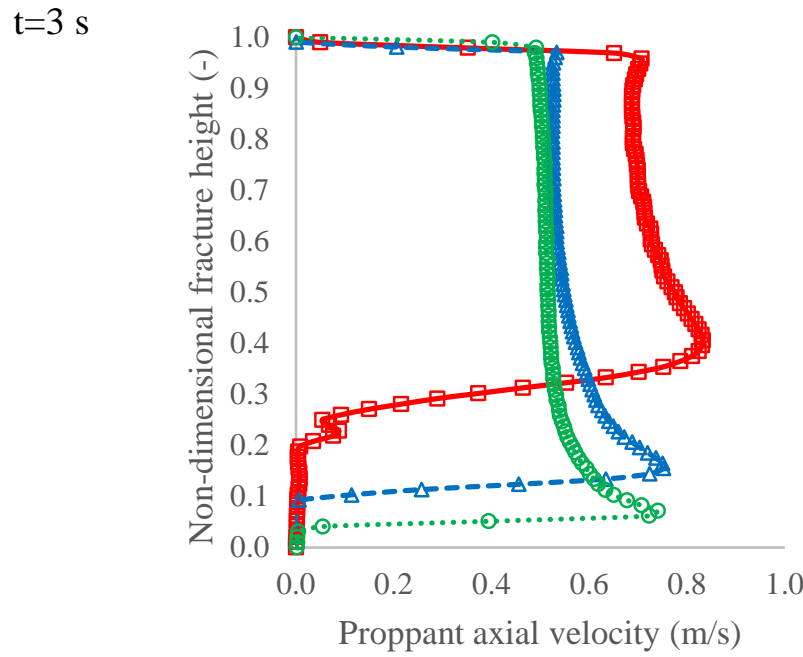

Legend
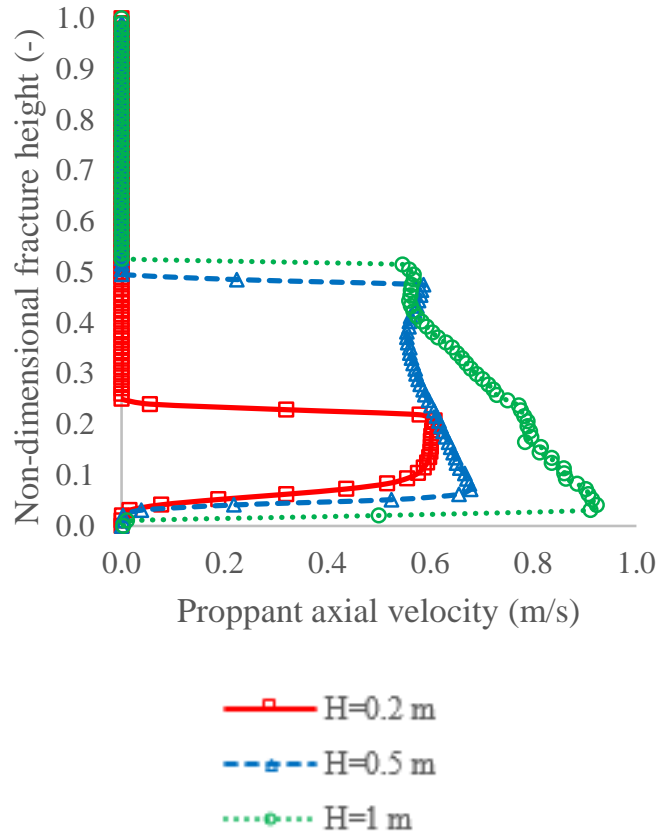

Fig. 23 Comparison of the proppant axial velocity with the non-dimensional fracture height for different fracture height cases $\mathrm{H}=0.2 \mathrm{~m}, 0.5 \mathrm{~m}$ and $1 \mathrm{~m}$ at two different locations ( $\mathrm{x}=0.2 \mathrm{~m}$ and $\mathrm{x}=1.4 \mathrm{~m}$ ) inside the fracture

\subsection{Comparison of Foam vs Water as fracturing fluid}

One of the significant problems faced in the shale gas reservoirs during proppant transport is the quick deposition of the proppant due to the low viscosity and lower capability to suspend the proppants for slick water. A case study is designed now to simulate Non-Newtonian fluid (Foam) that in the experiment has been reported to have better suspension capability than slick water, due to higher apparent viscosity. Some of the assumptions used to numerically model foam injection in the Hybrid model are as follows-

1. High quality and uniform foam (dry foam) is assumed. No effect of foam drainage and foam microstructure is accounted for in the model.

2. Laminar flow for foam has been assumed with Isothermal condition.

3. The experimental data for foam is used from the experimental study of Tong et al. (2017)

4. Herschel Buckley model is used to account for the rheological properties of the foam.

The key properties used to model foam injection in the current study are summarised in Table 3.

Table 3

Physical properties of foam as a fracturing fluid used in the simulation

\begin{tabular}{|l|l|}
\hline Specific gravity & 0.3 \\
\hline Fluid inlet velocity & $0.5 \mathrm{~m} / \mathrm{s}$ \\
& \\
\hline Viscosity & Herschel Buckley model \\
$\mathrm{K}$ & $\begin{array}{l}1.77 \mathrm{~N} \cdot \mathrm{s}^{\mathrm{n}} / \mathrm{m}^{2}(\mathrm{Gu} \text { and Mohanty, 2014) } \\
\text { @T }=308 \mathrm{~K}, \mathrm{P}=9.65 \mathrm{MPa}\end{array}$ \\
$\mathrm{n}$ & 0.45 \\
\hline Proppant volume fraction & 0.20 \\
& \\
\hline
\end{tabular}


Fig. 24 is the contour plots of proppant volume fraction at fracture mid-plane for different time step and shows all the comparison of foam vs water based fracturing fluid. Fig. 24 shows that as reported in the experiment, the foam has improved capability to suspend proppants, and the proppant bed height and bed length is lower for the foam injection, with greater proppant suspension layer, compared with the water injection.

The time evolution plot (Fig. 25 and Fig. 26) for the proppant volume fraction and proppant axial velocity with the non-dimensional fracture height at the two vertical cross sections $\mathrm{x}=0.2$ $\mathrm{m}$ and $1.4 \mathrm{~m}$ from the inlet show that, the proppant suspension layer for the foam case is significantly higher compared with the water case, which enhances the ability for the fracturing fluid to transport proppants to a more considerable distance inside fractures. Moreover, with time the suspended proppants deposits and forms proppant bed. This comparison study further suggests that using foam as a fracturing fluid have the potential to mitigate the challenge of quick deposition of proppant in shale gas reservoirs.

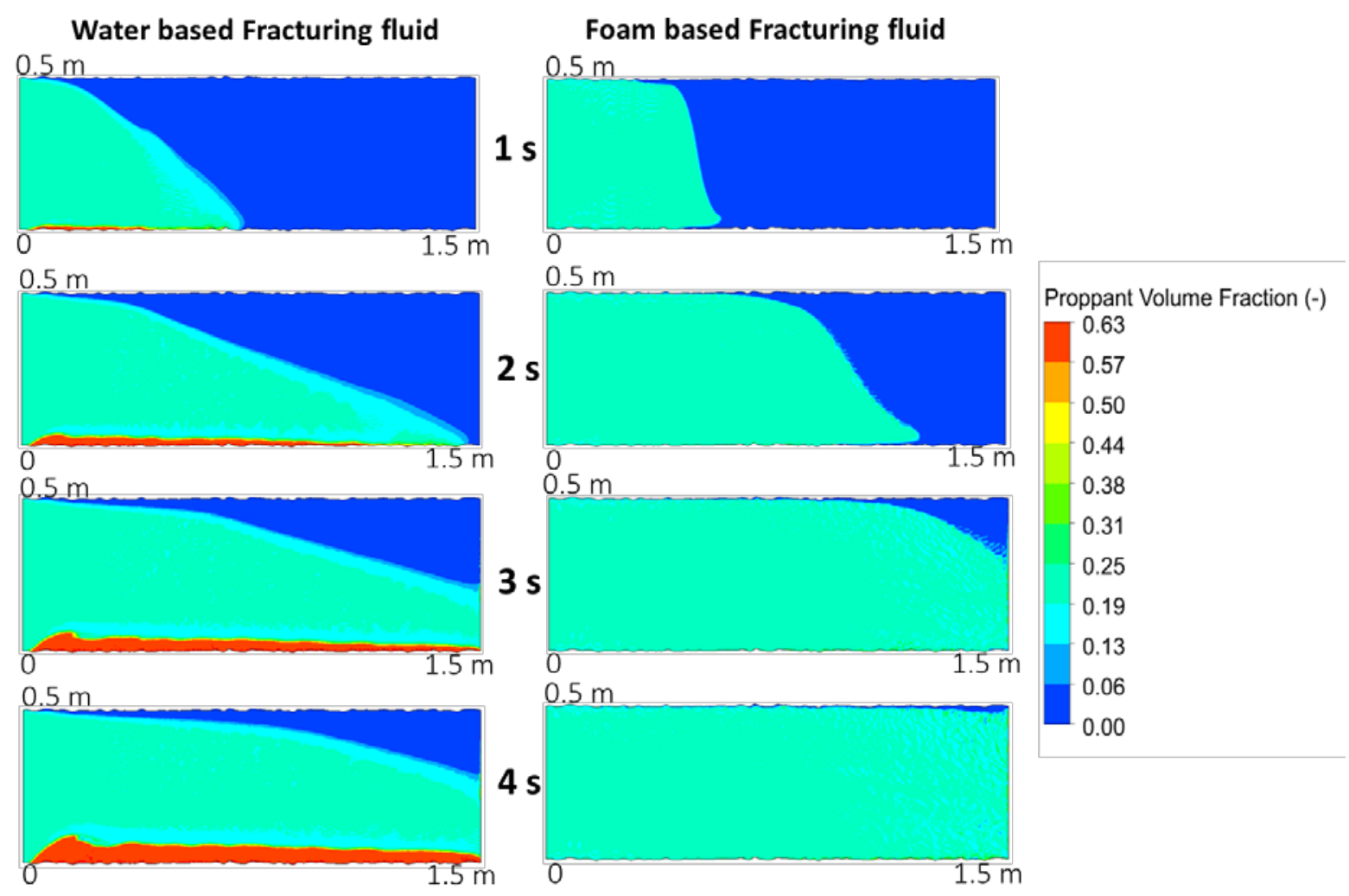

Fig. 24 Contour plot showing proppant volume fraction comparison of foam based fracturing fluid with a water-based fracturing fluid at a different time interval 
@x=0.2 m from inlet

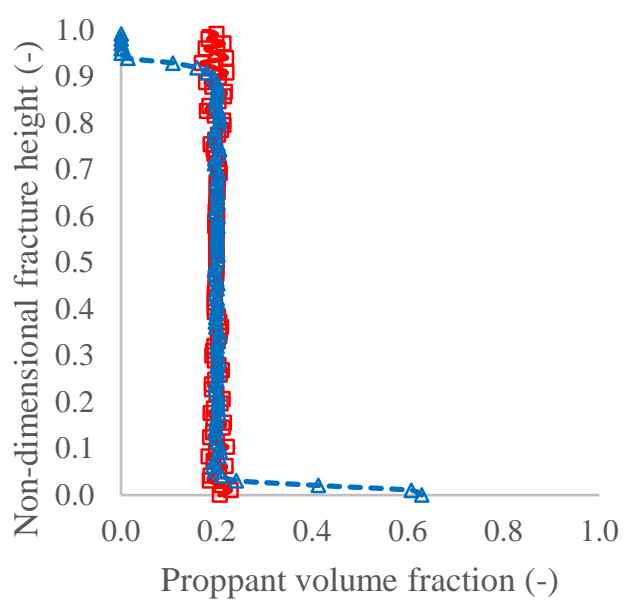

$\mathrm{t}=2 \mathrm{~s}$

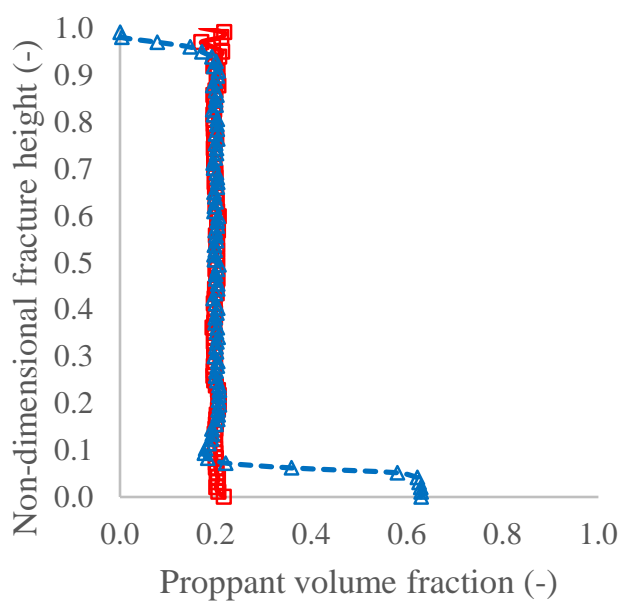

$\mathrm{t}=3 \mathrm{~s}$

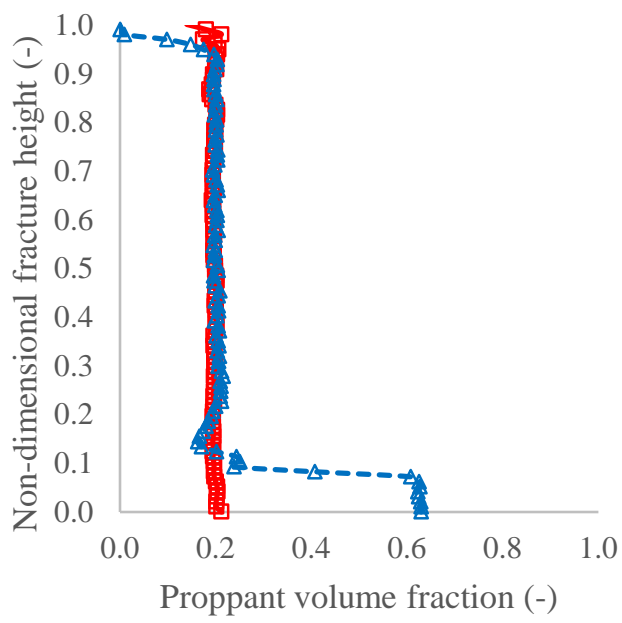

Legend
$@ x=1.4 \mathrm{~m}$ from inlet
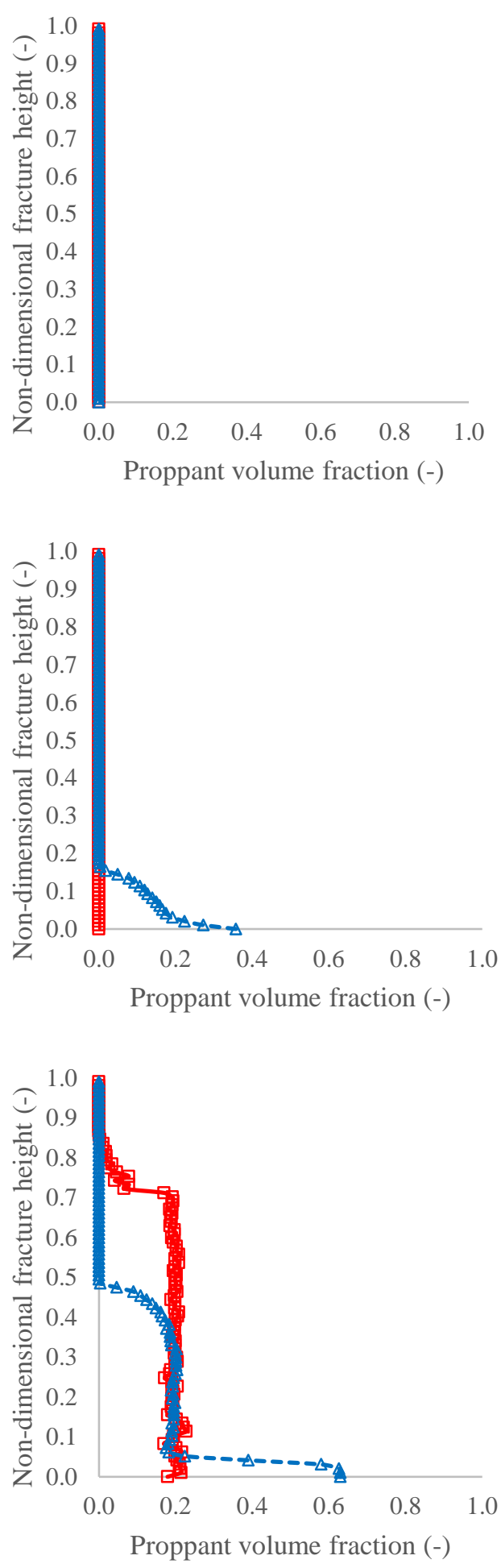

Fig. 25 Comparison of the proppant volume fraction with the non-dimensional fracture height for foam and water-based fracturing fluid at two different locations ( $x=0.2 \mathrm{~m}$ and $\mathrm{x}=1.4 \mathrm{~m}$ ) inside the fracture 
@ $=0.2 \mathrm{~m}$ from inlet

$\mathrm{t}=1 \mathrm{~s}$

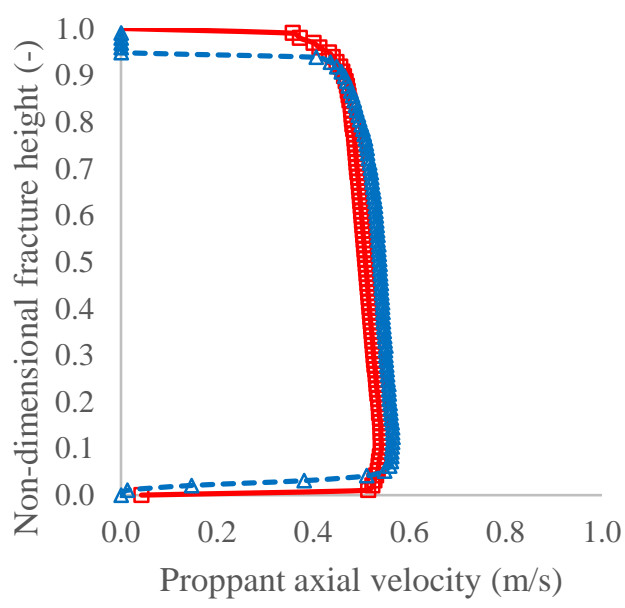

$t=2 \mathrm{~s}$

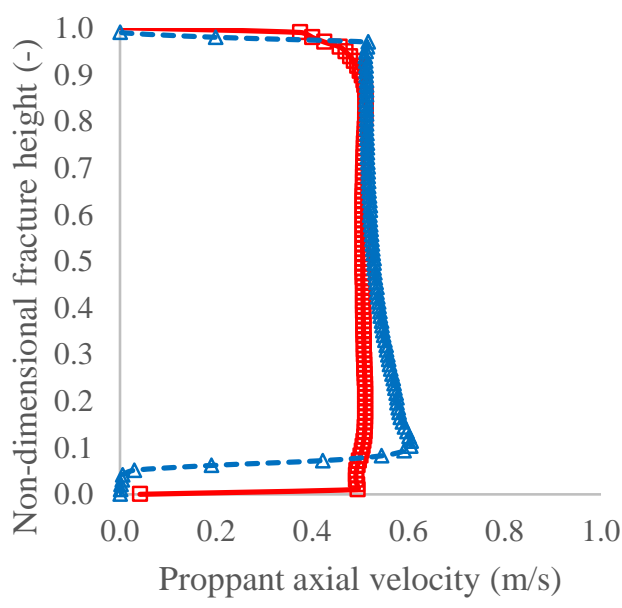

$\mathrm{t}=3 \mathrm{~s}$

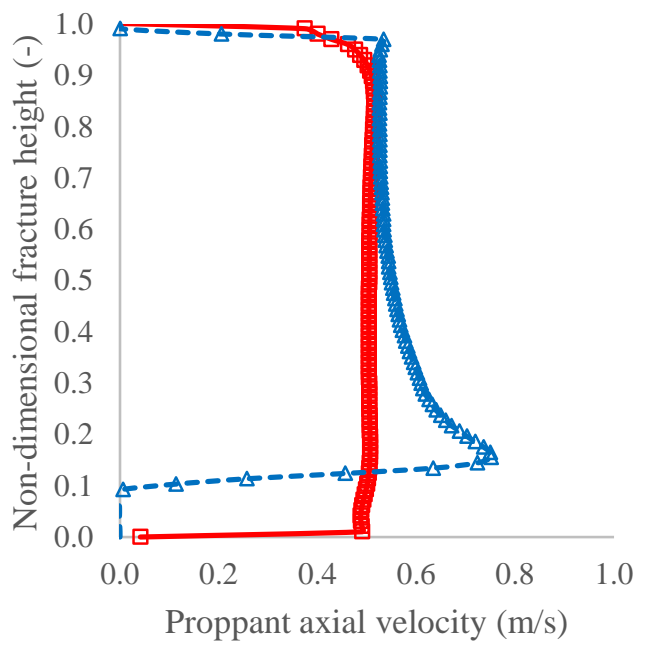

Legend @x=1.4 m from inlet
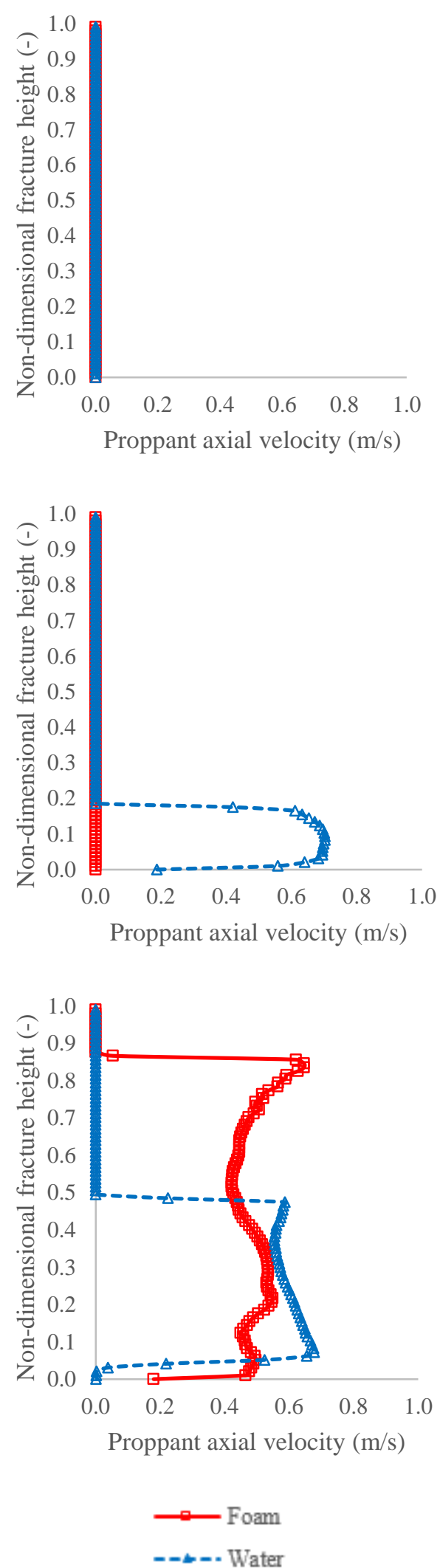

Fig. 26 Comparison of the proppant axial velocity with the non-dimensional fracture height for foam and water-based fracturing fluid at two different locations $(x=0.2 \mathrm{~m}$ and $\mathrm{x}=1.4 \mathrm{~m})$ inside the fracture 


\section{Conclusions}

Numerical simulation of proppant movement is studied within the hydraulic fracture using the hybrid method in which leak-off from the fracture wall and fracture roughness are modelled together. The model was validated with the reported experimental study and show good agreement. The simulation results suggest that neglecting the fracture roughness in the proppant transport model can result in over predicting the proppant bed length and underpredicting the proppant suspension layer by $10-15 \%$. Furthermore, neglecting the fluid leak-off effect can result in under predicting the proppant bed height by $10-50 \%$ and over predicting the proppant suspension layer by $10-50 \%$. The parametric study was performed to understand the proppant settling and transport mechanism by the variation in injection velocity, proppant concentration, fracture height, and use of foam as fracturing fluid. The sensitivity analysis of injection velocity shows that it is one of the key factors during Hydraulic Fracturing design. For low viscosity fluid like slickwater, higher injection velocity can have higher proppant concentration in the suspension and result in transporting proppant to a greater distance inside the fracture. The sensitivity analysis of proppant concentration shows that proppant concentration has a complex effect on proppant transport, such as proppant settling velocity, the rate of proppant bed buildup. The higher proppant concentration can help to reach the equilibrium height quickly, higher proppant velocity in the longitudinal direction and longer proppant bed length.

The comparison of foam injection with water injection shows that foam has improved capability to suspend proppants and using foam as a fracturing fluid have the potential to mitigate the challenge of quick deposition of proppant in shale gas reservoirs. Considering the applicability of the hybrid model for rough fractures, the current study suggests that the hybrid method can be used for practical problems of petroleum engineering interests for proppant distribution and settling. The current study has enhanced the understanding of complex proppant transport phenomenon in hydraulic fractures with fluid leak-off by capturing the proppant-fracturing fluid interaction and inter-particle physics accurately using the advanced computational methods.

\section{Acknowledgement}

This research is supported by the School of Engineering, Robert Gordon University, Aberdeen, United Kingdom.

\section{Conflicts of Interest}

The authors declare no conflicts of interest.

\section{References}

Alotaibi, M.A., Miskimins, J.L., 2015. Slickwater proppant transport in complex fractures: new experimental findings \& scalable correlation. In: Paper SPE-174828-MS, SPE Annual Technical Conference and Exhibition, 28-30 September, Houston, Texas, USA. Society of Petroleum Engineers. https://doi.org/10.2118/174828-MS.

Banerjee, S., Chan, A., 1980. Separated flow models-I. Analysis of the averaged and local instantaneous formulations. Int. J. Multiphas. Flow. 6, 1-24. https://doi.org/10.1016/03019322(80)90036-1.

Barree, R., Conway, M., 1994. Experimental and numerical modeling of convective proppant transport. In: Paper SPE-28564-MS, SPE Annual Technical Conference and Exhibition, 2528 September, New Orleans, Louisiana. Society of Petroleum Engineers. https://doi.org/10.2118/28564-MS.

Basu, D., Das, K., Smart, K., Ofoegbu, G., 2015. Comparison of Eulerian-Granular and discrete element models for simulation of proppant flows in fractured reservoirs. In: Paper IMECE2015-50050, ASME 2015 International Mechanical Engineering Congress and 
USA, 13-19 November, 2015. American Society of Mechanical Engineers, V07BT09A012. https://doi.org/10.1115/IMECE2015-50050.

Belyadi, H., Fathi, E., Belyadi, F., 2016. Hydraulic Fracturing in Unconventional Reservoirs: Theories, Operations, and Economic Analysis. Gulf Professional Publishing.

Blocken, B., Carmeliet, J., Stathopoulos, T., 2007. CFD evaluation of wind speed conditions in passages between parallel buildings - effect of wall-function roughness modifications for the atmospheric boundary layer flow. J. Wind Eng. Ind. Aerodyn. 95, 941-962. https://doi.org/10.1016/j.jweia.2007.01.013.

Bokane, A.B., Jain, S., Deshpande, Y.K., Crespo, F., 2013. Transport and distribution of proppant in multistage fractured horizontal wells: a CFD simulation approach. In: Paper SPE-166096-MS, SPE Annual Technical Conference and Exhibition, 30 September-2 October, New Orleans, Louisiana, USA. Society of Petroleum Engineers. https://doi.org/10.2118/166096-MS.

Brannon, H.D., Wood, W.D., Wheeler, R.S., 2006. Large scale laboratory investigation of the effects of proppant and fracturing fluid properties on transport. In: Paper SPE-98005-MS, SPE International Symposium and Exhibition on Formation Damage Control, 15-17 February, Lafayette, Louisiana, USA. Society of Petroleum Engineers. https://doi.org/10.2118/98005-MS.

Briggs, S., Karney, B.W., Sleep, B.E., 2017. Numerical modeling of the effects of roughness on flow and eddy formation in fractures. J. Rock Mech. and Geotech. Eng. 9, 105-115. https://doi.org/10.1016/j.jrmge.2016.08.004.

Carter, R., 1957. Derivation of the general equation for estimating the extent of the fractured area. Appendix I of "Optimum Fluid Characteristics for Fracture Extension,” Drilling and Production Practice, GC Howard and CR Fast, New York, New York, USA, American Petroleum Institute, 261-269.

Clifton, R., Wang, J., 1988. Multiple fluids, proppant transport, and thermal effects in threedimensional simulation of hydraulic fracturing. In: Paper SPE-18198-MS, SPE Annual Technical Conference and Exhibition, 2-5 October, Houston, Texas. Society of Petroleum Engineers. https://doi.org/10.2118/18198-MS.

Deng, S., Li, H., Ma, G., Huang, H., Li, X., 2014. Simulation of shale-proppant interaction in hydraulic fracturing by the discrete element method. Int. J. Rock Mech. and Min. Sci. 70, 219-228. https://doi.org/10.1016/j.ijrmms.2014.04.011.

Donaldson, E.C., Alam, W., Begum, N., 2014. Hydraulic fracturing explained: Evaluation, implementation, and challenges. Elsevier.

Gadde, P.B., Liu, Y., Norman, J., Bonnecaze, R., Sharma, M.M., 2004. Modeling proppant settling in water-fracs. In: Paper SPE-89875-MS, SPE Annual Technical Conference and Exhibition, 26-29 September, Houston, Texas. Society of Petroleum Engineers. https://doi.org/10.2118/89875-MS.

Gidaspow, D., 1994. Multiphase flow and fluidization: continuum and kinetic theory descriptions. Academic press.

Gidaspow, D., Bezburuah, R., Ding, J., 1991. Hydrodynamics of circulating fluidized beds: kinetic theory approach. Illinois Inst. of Tech., Chicago, IL (United States). Dept. of Chemical Engineering.

Gu, Q., Hoo, K.A., 2014. Evaluating the performance of a fracturing treatment design. Ind Eng Chem Res. 53, 10491-10503. https://doi.org/10.1021/ie404134n.

Gu, M., Mohanty, K.K., 2014. Effect of foam quality on effectiveness of hydraulic fracturing in shales. Int. J. Rock Mech. and Min. Sci. 70, 273-285. https://doi.org/10.1016/j.ijrmms.2014.05.013.

Hosseini, H., Tsau, J., Peltier, E., Barati, R., 2018. Lowering Fresh Water Usage in Hydraulic Fracturing by Stabilizing scCO 2 Foam with Polyelectrolyte Complex Nanoparticles Prepared in High Salinity Produced Water. In: Paper SPE-189555-MS, SPE International Conference and Exhibition on Formation Damage Control, 7-9 February, Lafayette, Louisiana, USA. Society of Petroleum Engineers. https://doi.org/10.2118/189555-MS. 
Hu, X., Wu, K., Li, G., Tang, J., Shen, Z., 2018. Effect of proppant addition schedule on the proppant distribution in a straight fracture for slickwater treatment. J. Pet. Sci. Eng. 167, 110-119. https://doi.org/10.1016/j.petrol.2018.03.081.

Jakobsen, H.A., 2014. Chemical reactor modeling: multiphase reactive flows. Springer Science \& Business Media.

Johnson, P.C., Jackson, R., 1987. Frictional-collisional constitutive relations for granular materials, with application to plane shearing. J. Fluid Mech. 176, 67-93. https://doi.org/10.1017/S0022112087000570.

Kern, L., Perkins, T., Wyant, R., 1959. The mechanics of sand movement in fracturing. J. Pet. Technol. 11, 55-57.

Kong, X., McAndrew, J., Cisternas, P., 2016. CFD study of using foam fracturing fluid for proppant transport in hydraulic fractures. In: Paper SPE-183549-MS, Abu Dhabi International Petroleum Exhibition \& Conference, 7-10 November, Abu Dhabi, UAE. Society of Petroleum Engineers. https://doi.org/10.2118/183549-MS.

Lange, T., Sauter, M., Heitfeld, M., Schetelig, K., Brosig, K., Jahnke, W., Kissinger, A., Helmig, R., Ebigbo, A., Class, H., 2013. Hydraulic fracturing in unconventional gas reservoirs: risks in the geological system part 1. Environ. Earth Sci. 70, 3839-3853. https://doi.org/10.1007/s12665-013-2803-3.

Li, Q., Xing, H., Liu, J., Liu, X., 2015. A review on hydraulic fracturing of unconventional reservoir. Petroleum. 1, 8-15. https://doi.org/10.1016/j.petlm.2015.03.008.

Liu, Y., 2006. Settling and hydrodynamic retardation of proppants in hydraulic fractures. Doctoral dissertation. The University of Texas at Austin.

Lun, C., Savage, S.B., Jeffrey, D., Chepurniy, N., 1984. Kinetic theories for granular flow: inelastic particles in Couette flow and slightly inelastic particles in a general flowfield. J. Fluid Mech. 140, 223-256. https://doi.org/10.1017/S0022112084000586.

Mahdavi, M., Sharifpur, M., Meyer, J.P., 2015. CFD modelling of heat transfer and pressure drops for nanofluids through vertical tubes in laminar flow by Lagrangian and Eulerian approaches. Int. J. Heat Mass Transfer. 88, 803-813. https://doi.org/10.1016/j.ijheatmasstransfer.2015.04.112.

Menter, F., 1993. Zonal two equation kw turbulence models for aerodynamic flows. In: 23rd fluid dynamics, plasmadynamics, and lasers conference, 2906. https://doi.org/10.2514/6.1993-2906.

Ogilvie, S.R., Isakov, E., Glover, P.W., 2006. Fluid flow through rough fractures in rocks. II: A new matching model for rough rock fractures. Earth Planet. Sci. Lett. 241, 454-465. https://doi.org/10.1016/j.epsl.2005.11.041.

Patankar, S., 1980. Numerical heat transfer and fluid flow. CRC press.

Patankar, N.A., Joseph, D.D., 2001. Modeling and numerical simulation of particulate flows by the Eulerian-Lagrangian approach. Int. J. Multiphas. Flow. 27, 1659-1684. https://doi.org/10.1016/S0301-9322(01)00021-0.

Roostaei, M., Nouri, A., Fattahpour, V., Chan, D., 2018. Numerical simulation of proppant transport in hydraulic fractures. J. Pet. Sci. Eng. 163, 119-138. https://doi.org/10.1016/j.petrol.2017.11.044.

Sahai, R., Miskimins, J.L., Olson, K.E., 2014. Laboratory results of proppant transport in complex fracture systems. In: Paper SPE-168579-MS, SPE Hydraulic Fracturing Technology Conference, 4-6 February, The Woodlands, Texas, USA. Society of Petroleum Engineers. https://doi.org/10.2118/168579-MS.

Savage, S., Jeffrey, D., 1981. The stress tensor in a granular flow at high shear rates. J. Fluid Mech. 110, 255-272. https://doi.org/10.1017/S0022112081000736.

Schols, R., Visser, W., 1974. Proppant bank buildup in a vertical fracture without fluid loss. In: Paper SPE-4834-MS, SPE European Spring Meeting, 29-30 May, Amsterdam, Netherlands. Society of Petroleum Engineers. https://doi.org/10.2118/4834-MS.

Snider, D.M., 2001. An Incompressible Three-Dimensional Multiphase Particle-in-Cell Model for Dense Particle Flows. J. Comput. Phys. 170, 523-549. https://doi.org/10.1006/jcph.2001.6747. 
Speight, J.G., 2016. Deep shale oil and gas. Gulf Professional Publishing. Tong, S., Mohanty, K., 2017. Proppant Placement in Secondary Fractures. In: Paper URTEC2671549-MS, SPE/AAPG/SEG Unconventional Resources Technology Conference, 24-26 July, Austin, Texas, USA. Society of Exploration Geophysicists, American Association of Petroleum Geologists, Society of Petroleum Engineers, 1907-1918. https://doi.org/10.15530/URTEC-2017-2671549.

Tong, S., Mohanty, K.K., 2016. Proppant transport study in fractures with intersections. Fuel. 181, 463-477. https://doi.org/10.1016/j.fuel.2016.04.144.

Tong, S., Singh, R., Mohanty, K.K., 2017. Proppant Transport in Fractures with Foam-Based Fracturing Fluids. In: Paper SPE-187376-MS, SPE Annual Technical Conference and Exhibition, 9-11 October, San Antonio, Texas, USA. Society of Petroleum Engineers. https://doi.org/10.2118/187376-MS.

Tong, S., Singh, R., Mohanty, K.K., 2018. A visualization study of proppant transport in foam fracturing fluids. J. Nat. Gas Sci. Eng. 52, 235-247. https://doi.org/10.1016/j.jngse.2018.01.030.

Tsai, K., Fonseca, E., Lake, E., Degaleesan, S., 2012. Advanced computational modeling of proppant settling in water fractures for shale gas production. SPE J. 18, 50-56. https://doi.org/10.2118/151607-PA.

Van Wachem, B., Schouten, J., Van den Bleek, C., Krishna, R., Sinclair, J., 2001. Comparative analysis of CFD models of dense gas-solid systems. AIChE J. 47, 1035-1051. https://doi.org/10.1002/aic.690470510.

Versteeg, H.K., Malalasekera, W., 2007. An introduction to computational fluid dynamics: the finite volume method. Pearson Education.

Wang, J., Elsworth, D., Ma, T., 2018. Conductivity evolution of proppant-filled hydraulic fractures. In: Paper ARMA-2018-111, 52nd U.S. Rock Mechanics/Geomechanics Symposium, 17-20 June, Seattle, Washington. American Rock Mechanics Association.

Wang, J., Joseph, D.D., Patankar, N.A., Conway, M., Barree, R.D., 2003. Bi-power law correlations for sediment transport in pressure driven channel flows. Int. J. Multiphas. Flow. 29, 475-494. https://doi.org/10.1016/S0301-9322(02)00152-0.

Wu, C., Sharma, M.M., 2016. Effect of Perforation Geometry and Orientation on Proppant Placement in Perforation Clusters in a Horizontal Well. In: Paper SPE-179117-MS, SPE Hydraulic Fracturing Technology Conference, 9-11 February, The Woodlands, Texas, USA. Society of Petroleum Engineers. https://doi.org/10.2118/179117-MS.

Yang, S., Siddhamshetty, P., Kwon, J.S., 2017. Optimal pumping schedule design to achieve a uniform proppant concentration level in hydraulic fracturing. Comput. Chem. Eng. 101, 138-147. https://doi.org/10.1016/j.compchemeng.2017.02.035.

Yew, C.H., Weng, X., 2014. Mechanics of hydraulic fracturing. Gulf Professional Publishing.

Yuan, J., Jiang, R., Zhang, W., 2018. The workflow to analyze hydraulic fracture effect on hydraulic fractured horizontal well production in composite formation system. Adv. GeoEner. Res. 2, 319-342.

Zhang, G., Li, M., Gutierrez, M., 2016. Numerical simulation of proppant distribution in hydraulic fractures in horizontal wells. J. Nat. Gas Sci. Eng. https://doi.org/10.1016/j.jngse.2016.10.043.

\section{Nomenclature}

$\mathrm{C}_{\mathrm{D}} \quad$ Drag coefficient

d Particle diameter (size)

$\overrightarrow{\mathrm{e}}_{12} \quad$ Unit vector

$\overrightarrow{\mathrm{F}}_{\text {drag }} \quad$ Drag force

$\overrightarrow{\mathrm{F}}_{\text {gravitation }} \quad$ Gravitational force

$\overrightarrow{\mathrm{F}}_{1} \quad$ Lift force

$\overrightarrow{\mathrm{F}}_{\text {other }} \quad$ Additional force term 


\begin{tabular}{|c|c|c|}
\hline 911 & $\overrightarrow{\mathrm{F}}_{\mathrm{vm}}$ & Virtual mass force \\
\hline 912 & $\overrightarrow{\mathrm{F}}$ & External body force term \\
\hline 913 & $\mathrm{~F}_{1} / \mathrm{F}_{2}$ & Force on particle 1/particle2 \\
\hline 914 & $\mathrm{~F}_{\mathrm{i}}$ & Source term for the flow through porous media \\
\hline 915 & $\mathrm{~g}$ & Acceleration due to gravity \\
\hline 916 & $\mathrm{~g}_{0, \mathrm{ss}}$ & Radial distribution function \\
\hline 917 & $\mathrm{H}$ & Height of slot, \\
\hline 918 & Ho & Height of slurry flow area \\
\hline 919 & $\overline{\overline{\mathrm{I}}}$ & Unit tensor \\
\hline 920 & $\mathrm{~K}_{\mathrm{ls}} / \mathrm{K}_{\mathrm{sl}}$ & Momentum exchange coefficient \\
\hline 921 & $\overrightarrow{\mathrm{M}}_{\mathrm{ls}} / \overrightarrow{\mathrm{M}} \mathrm{sl}_{\mathrm{l}}$ & Interfacial momentum transfer \\
\hline 922 & $\mathrm{P}$ & pressure \\
\hline 923 & $\mathrm{P}_{\mathrm{sf}}$ & Solids frictional pressure \\
\hline 924 & $\operatorname{Re}$ & Reynolds number \\
\hline 925 & $\mathrm{R}_{\mathrm{gl}}$ & Gravity Reynolds number for the fluid phase \\
\hline 926 & $\mathrm{R}_{\mathrm{gp}}$ & Gravity Reynolds number for the proppant phase \\
\hline 927 & $\mathrm{~S}_{\mathrm{m}}$ & Mass source term \\
\hline 928 & $\mathrm{~S}_{\mathrm{u}}$ & Momentum source term \\
\hline 929 & $\mathrm{t}$ & current time step \\
\hline 930 & $t_{p}$ & particle time step \\
\hline 931 & $\mathrm{w}$ & Width of slot \\
\hline 932 & $\mathrm{x}$ & Displacement \\
\hline 933 & & \\
\hline 934 & \multicolumn{2}{|c|}{ Greek symbols: } \\
\hline 935 & $\vec{v}_{12}$ & Relative velocity between particles \\
\hline 936 & $\overline{\bar{\tau}}$ & Stress-strain tensor \\
\hline 937 & $\mathrm{k}_{\Theta_{\mathrm{s}}}$ & diffusion coefficient \\
\hline 938 & $\vec{v}$ & Velocity \\
\hline 939 & $\alpha_{\mathrm{s}, \max }$ & maximum packing fraction limit of solids \\
\hline 940 & $\alpha_{\mathrm{s}, \min }$ & minimum frictional volume fraction \\
\hline 941 & $\gamma_{\Theta_{s}}$ & granular energy dissipation \\
\hline 942 & $\varepsilon_{\mathrm{D}}$ & Fraction of diameter for allowable overlap \\
\hline 943 & $\Theta_{\mathrm{s}}$ & granular temperature \\
\hline 944 & $\mu_{\mathrm{s}, \mathrm{col}}$ & granular phase collisional viscosity \\
\hline 945 & $\mu_{\mathrm{s}, \mathrm{fr}}$ & granular phase frictional viscosity \\
\hline 946 & $\mu_{\mathrm{s}, \mathrm{kin}}$ & granular phase kinetic viscosity \\
\hline 947 & $\tau_{\mathrm{r}}$ & Particle relaxation time \\
\hline 948 & $\Phi_{\mathrm{ls}}$ & interphase granular energy transfer \\
\hline 949 & $\mathrm{~K}$ & Spring constant \\
\hline 950 & $\alpha$ & Volume fraction \\
\hline 951 & $\gamma$ & Damping coefficient \\
\hline 952 & $\delta$ & Overlap \\
\hline 953 & $\eta$ & Coefficient of restitution \\
\hline 954 & $\lambda$ & Bulk viscosity \\
\hline 955 & $\mu$ & Dynamic viscosity \\
\hline
\end{tabular}


Density

$957 \mathrm{k}$

Permeability

$958 \theta$

friction angle

959 Subscripts:

960

Phase (liquid or solid)

961

Liquid phase

$962 \mathrm{p}$

Particle phase

$963 \mathrm{~s}$

Granular phase

964 